\title{
An Input-Output Model for Analyzing Carbon Emissions in the Urban Agglomeration of the Three Northeastern Provinces in China
}

\author{
Jiazheng Sun ${ }^{1}$, Hongkuan Zang²*, Zhengping Liu ${ }^{3}$, Yu Han ${ }^{4}$, Xuyu Zhang \\ ${ }^{1}$ College of Environmental Science and Engineering, North China Electric Power University, Beijing 102206, China \\ ${ }^{2}$ Chinese Academy of Environmental Planning, Beijing 100012, China \\ ${ }^{3}$ Development Research Center of the Ministry of Water Resources of P.R. China, Beijing 100038, China \\ ${ }^{4}$ College of Life and Environmental Science, Minzu University of China, Beijing 100081, China \\ ${ }^{5}$ School of Engineering, University of Science and Technology Liaoning, An'shan 114051, Liaoning, China
}

Received: 24 February 2020

Accepted: 26 April 2020

\begin{abstract}
Carbon emissions and carbon flow within a specific area have been studied extensively, but little is known about the effects of inter-regional material and energy exchanges on carbon emissions. In this study, we examined an urban agglomeration in Northeastern China. A carbon emission model was established based on input-output analysis, and robustness analysis was used to test the system's stability. A new factor for indirect emission dominance intensity was developed to distinguish the significances of indirect emissions and direct emissions. Sectoral control and dependence relationships were explored by ecological network analysis. Results showed that carbon emissions from primary energy consumption were 2.34 times higher than those from secondary energy consumption. The indirect carbon emissions were more than double the direct emissions. The largest direct and indirect carbon emissions come from the advanced manufacturing sector, and the materials and energy conversion sector, respectively. In urban agglomeration, the exploitation relationship between sectors was dominant, suggesting that the structure of the system needs to be improved. Our results provide sector-specific information to help each sector to adjust industrial planning for emission reductions.
\end{abstract}

Keywords: urban agglomerations, carbon emission model, input-output analysis, energy consumption, indirect carbon emissions

\section{Introduction}

The Three Northeastern Provinces (TNP; Heilongjiang, Jilin, and Liaoning provinces), known as "the industrial cradle of new China" $[1,2]$, contribute strongly to the economy of China. The TNP covers about $8.20 \%$ of China's land area, and its economy accounts for $8 \%$ of China's gross domestic product; however, the energy consumption in the TNP accounts for almost $11.5 \%$ of China's total energy consumption [3]. The main energy consumption in the TNP is

*e-mail: zanghongkuan@163.com 
primary energy (coal burning). Moreover, according to Global Carbon Project publications, China is the largest carbon emitter with 10 billion tons of carbon emissions [4], while the TNP, as one of the largest carbon emitters within China, has reached 900 million tons [3]. Reducing carbon emissions within the TNP is therefore critical for the reduction of China's emissions and improvement of the global environment.

Researchers have conducted many studies aiming to analyze carbon emissions from different perspectives. For example, Zang et al. analyzed per-capita carbon dioxide emissions for different countries based on statistical methods [5]. Li et al. demonstrated how to adjust industrial structure to control carbon emissions by input-output analysis and social network analysis [3]. Salman et al. explored different impacts of export and import on direct carbon emissions across seven countries with a panel quantile regression approach [7]. Wang et al. identified the driving forces that influence carbon emissions from China's residential consumption through the economic input-output life-cycle assessment method [8]. However, to our knowledge, no researchers have yet studied the relationships among carbon emissions from the different components of an urban agglomeration, and have only analyzed the carbon emissions in a single city. In addition, the impacts of indirect emissions have been ignored in previous studies, and to our knowledge, no studies have explored the differences between carbon emissions and carbon flows of different energy types. Thus, it is essential to fully analyze the urban carbon emissions system to reveal economical emissions reduction pathways, and support sustailn order to explore the situation of carbon emissions and carbon flows in the TNP, inputoutput analysis (IOA) was adopted in this study, which was first proposed by Leontief to analyze the potential flows in an economic system [9]. Specifically, IOA has been used in quantifying mercury emission and flows [10], investigating carbon emissions from household consumption [11] and analyzing the effect of primary $\mathrm{PM}_{2.5}$ on human health [12]. Input-output (I-O) tables describe the sale and purchase relationships between producers and consumers within an economy at a disaggregated level [9]. Combining IOA and ecological network analysis (ENA) can analyze carbon flows from different perspectives well [13].

Ecological network analysis, a system analysis method, was first proposed by Lloret-Climent in 1978, and was used to analyze the indirect flows of different sectors and internal relationships [14]. Based on ENA, network utility analysis (NUA) [15] and network control analysis (NCA) [16] were developed to reflect mutual relationships among sectors and the degree of dependence of sectors on the system. Many researchers have combined these two methods to study natural element problems. For example, Zhai et al. explored the situation of inter-provincial water in the food trade to determine the inner relationships within sectors [17]. Fang and Chen analyzed the distribution of embodied carbon flows in socio-economic networks in China, and showed that the wealthy provinces had lower carbon emissions [18]. Wang et al. applied the methods to study the influence of different energy scenarios and energy mix in the water system, and found that sectoral nexus had a large impact on the water system [19]. Zhang et al. studied the water consumption structure and the mutual control relationships among different sectors, the results showed that the system is not in a mutualism state [20]. Moreover, ENA has also been widely accepted as a new method to study the food web [21], ecosystem trophic status [22], biological organs [23] and solar electric power systems [24]. These analyses revealed that the ENA provided complimentary insights, and combining ENA and IOA could provide a more comprehensive understanding of the complex urban agglomeration system [13].

To our knowledge, there are currently few studies on direct carbon emissions within urban agglomerations in China, most of which focus on direct emissions and interactions. It is important to explore indirect carbon emissions from economic and trade within the TNP. Furthermore, the differences between indirect carbon emissions and indirect carbon flow should also be taken seriously. In addition, the differences among energy types also have important impact on carbon emissions. These research gaps on indirect carbon emissions and analysis of flows and emission relationships in urban agglomerations therefore need to be addressed.

In this study, a new Carbon Emission Input-Output model (CEIO) was proposed to explore the interaction of carbon emissions among urban agglomeration in the TNP. The sectors of each province were integrated into seven sectors according to the similar carbon emission characteristics. The direct and indirect carbon emissions of the 21 sectors and carbon flows among sectors were calculated. In addition, a new index, indirect carbon emission dominance intensity (IE-DIT) was developed to explore major emission modes of the system. The dependencies of sectors were studied to reflect the sectoral control and dependence over the system with network control analysis. Three ecological relationships were also analyzed to imply the mutual relationships among sectors with network utility analysis. Moreover, a robustness analysis was introduced to examine the stability of the system. The results will be helpful for adjusting intersectoral relationships to reduce carbon emissions and formulating reduction policies.

\section{Methods and Data}

\section{Technical Framework and Model Construction}

A carbon emission input-output model (CEIO) was developed to study the interprovincial carbon emission from the perspective of ENA. Fig. 1 shows 


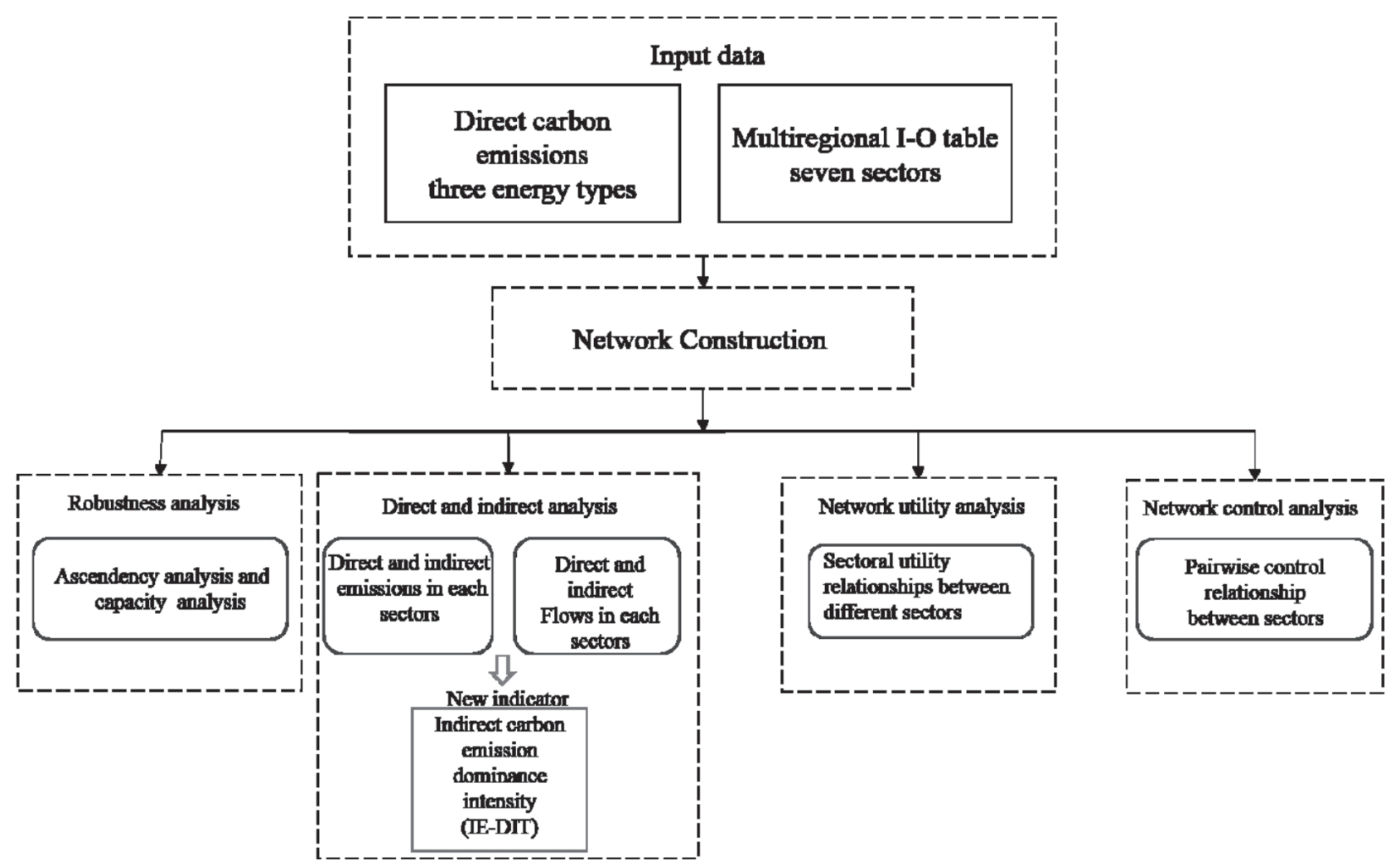

Fig. 1. Technical framework and model structure for the CEIO model.

the model framework for the carbon emission network. The economic flow data were taken as the basis of establishing carbon emission network, which can then reveal the interprovincial relationships. First, the system capacity, redundancy and robustness are calculated to conduct system stability. Then, based on assessment direct and indirect carbon emissions and flow pathways, the main emissions pathway can be determined and described by the new IE-DIT indicator. Furthermore, ENA is used to evaluate the degree of independence and functional relationships of different sectors.

The CEIO is established through the input-output Leontief framework [9], which can be developed to study carbon emission and emission relationships among different provinces and sectors. The CEIO consisted of three provinces, with seven sectors in each province as follows (Table 1): A, agriculture; M, mining; PM, prime manufacturing; AM, advanced manufacturing; ET, materials and energy transformation; C, construction; and TI, tertiary industry. There was therefore a total of 21 sectors. Using the embodied emission intensity, the economic input-output table was converted into the monetary input-output table [25].

$$
\begin{gathered}
\varepsilon=C[\mathbf{Z}-\mathbf{X}]^{-1} \\
\mathbf{P}=\varepsilon \mathbf{X}
\end{gathered}
$$

...where $C$ represents the carbon emissions of sectors of each province, $\varepsilon$ represents the embodied emission intensity factor, $\mathbf{X}$ represents the value flow matrix, and $\mathbf{Z}$ is a diagonal matrix which consists of the total output of each sector, $\mathbf{P}$ represents the embodied discharge intensity matrix [26].

The physical input-output tables were established through the carbon emission flow matrix, and the sum of carbon emissions of each province and sector was calculated by the following formula:

$$
G_{i j}=\sum_{i=1}^{n} g_{i j}
$$

...where $G_{i j}$ represents the total carbon emissions, $g_{i j}$ represents carbon emissions from sector $i$ to sector $j$. The results of the method are shown in Fig. 3 and Table S11.

According to equilibrium theory, for a system, inputs must be equal to outputs, in other words, the total carbon inflows from a sector must be equal to the carbon outflows from a sector [27]. Therefore, the total carbon flows can be calculated as follows:

$$
T_{i}=\sum_{i=1}^{n} f_{i j}+P_{i}
$$

...where $T_{i}$ represents the total carbon flow of sector $i$, $f_{i j}$ represents carbon flow from $i$ to $j$ and $P_{i}$ represents the initial resources flow into the whole system. The results of the method are shown in Fig. 4 and Table S5-S10. 
Table 1. Names of the seven sectors and of the components within each sector.

\begin{tabular}{|c|c|}
\hline Abbreviation & Sector \\
\hline A & $\begin{array}{l}\text { Farming, forest, livestock, and fishery } \\
\text { products. }\end{array}$ \\
\hline M & $\begin{array}{l}\text { Mining and washing of energy minerals, metal } \\
\text { and non-metal and other mining products. }\end{array}$ \\
\hline $\mathrm{PM}$ & Food and tobacco products, textile, paper, etc. \\
\hline $\mathrm{AM}$ & Chemicals, mineral products, equipment, etc. \\
\hline ET & $\begin{array}{c}\text { Electricity and heat and gas production, water } \\
\text { production. }\end{array}$ \\
\hline $\mathrm{C}$ & Construction. \\
\hline $\mathrm{TI}$ & $\begin{array}{c}\text { Transportation, services, financial industry, } \\
\text { etc. }\end{array}$ \\
\hline
\end{tabular}

\section{Network Control Analysis}

Network control analysis is a method that is used to study the dependence degree among different sectors [16]. In this study, the dependence of different sectors was expressed by carbon flows, which were represented by an intensity matrix as follows:

$$
\begin{gathered}
\mathbf{N}^{\prime}=\left(\mathbf{G}^{\prime}\right)^{0}+\left(\mathbf{G}^{\prime}\right)^{1}+\left(\mathbf{G}^{\prime}\right)^{2}+\cdots+\left(\mathbf{G}^{\prime}\right)^{\mathrm{m}}+\ldots=\left(\mathbf{I}-\mathbf{G}^{\prime}\right)^{-1} \\
\mathbf{G}^{\prime}=\left[g_{i j}^{\prime}\right]_{n^{* n}} \\
g_{i j}^{\prime}=f_{i j} / T_{i}
\end{gathered}
$$

...where $g_{i j}^{\prime}$ is the elements of non-dimensional carbon exchange intensity matrix $\mathbf{G}^{\prime}$. I represents the identity matrix. The matrix $\mathbf{Y}$, which represents the contribution of each sector, was obtained by multiplying the integral flow intensity matrix by the diagonal of the flow matrix [15]:

$$
\mathbf{Y}=\operatorname{diag}(\mathbf{T}) \mathbf{N}^{\prime}
$$

In previous research [27], the driving force weight $\left(W_{i}\right)$ and the pull force $\left(W_{j}\right)$ can be calculated. The driving force weight $\left(W_{i}\right)$ reveals the sectoral ability to deliver carbon to other sectors, and also represents the control degree of sector $i$ for other sectors. The pull force $\left(W_{j}\right)$ reflects the capability of sector $i$ to receive emissions of carbon from other sectors or the entire system, and represents the sector's "pull" on the other sectors through forward linkages [27]:

$$
W_{i}=\frac{\sum_{j=1}^{n} y_{i j}}{\sum_{i=1}^{n} \cdot \sum_{j=1}^{n} y_{i j}}
$$

$$
W_{j}=\frac{\sum_{i=1}^{n} y_{i j}}{\sum_{i=1}^{n} \cdot \sum_{j=1}^{n} y_{i j}}
$$

Based on the NCA, effective advice can be provided relating to reducing carbon emissions through reducing intersectoral flow. The results of the method are shown in Fig. 6 and Table S1.

\section{Network Utility Analysis}

Network utility analysis is an effective method that can reflect the mutual relationship between different sectors [15]. The mutual relation of two sectors can be found through using the direct utility matrix $\mathbf{D}=\left[d_{i j}\right]$ and the integral utility intensity matrix $\mathbf{U}=\left[u_{i j}\right]$.

$$
\mathbf{D}=\left[d_{i j}\right]=\frac{\left(f_{i j}-f_{j i}\right)}{T_{i}}
$$

$\mathbf{U}=\left[u_{i j}\right]=\mathbf{D}^{0}+\mathbf{D}^{1}+\mathbf{D}^{2}+\cdots+\mathbf{D}^{k}+\cdots=(\mathbf{I}-\mathbf{D})^{-1}$

The nature of the relationships between different sectors can be judged by using the positive and negative signs of the elements in the integral utility matrix. In this study, four relationships were reflected: mutualism $(+,+)$, competition $(-,-)$, and exploitation $(+,-$ or,-+$)$ [27]. The results of the method are shown in Fig. 5 and Table S2-S4.

\section{Robustness Analysis}

The healthy level of the system can be assessed by two indicators: capacity and ascendency. The ascendency $A M I$, capacity $H c$, and robustness $R$ are obtained through Equation (13) to Equation (16):

$$
\begin{gathered}
A M I=K \sum_{i j}\left(\frac{P_{i j}}{\sum_{i j} P_{i j}}\right) \log \left(\frac{P_{i j} \sum_{i j} P_{i j}}{\sum_{i} P_{i j} \sum_{j} P_{i j}}\right) \\
H_{c}=-K \sum_{i j}\left(\frac{P_{i j}}{\sum_{i j} P_{i j}}\right) \log \left(\frac{P_{i j}^{2}}{\sum_{i} P_{i j} \sum_{j} P_{i j}}\right) \\
a=A M I /\left(A M I+H_{c}\right) \\
R=-\operatorname{alog}(a)
\end{gathered}
$$

...where $a$ is the degree of order and $K$ is the scale coefficient $(K=1)$.

The results of the method are shown in Fig. 2. 


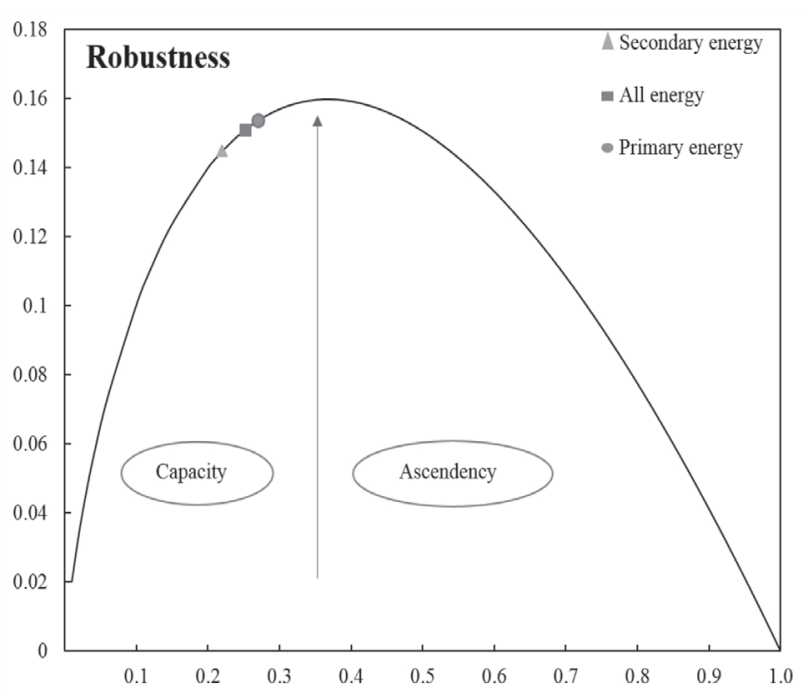

Fig. 2. Relationships between system robustness and the degree of order. The y-axis is dimensionless.

\section{Indirect Emission Dominance Intensity Analysis}

Exploration of the emission dominance of direct emissions and indirect emissions is essential to adjust the use of energy types of each province. Through further analysis, the adjustment of energy use of each sector can also be found. The indirect emission dominance intensity of sector $\left(F_{i}\right)$ can be obtained as follows:

$$
F_{i}=\frac{I g_{i}}{\sum I g_{i}+E g_{i}}
$$

...where $I g_{i}$ is indirect emissions of sector $i$ and $E g_{i}$ is the direct emissions of sector $i$. The results of the method are shown in Table 2.

\section{Study Site and Data}

The TNP of China, as a national industrial base, has made historic contributions to the economic development and growth of China. However, pollution problems have occurred corresponding to this economic development, including excessive carbon emissions. By the end of 2012, the total carbon emissions of TNP had reached $960 \mathrm{Mt}$. In 2008, the total primary energy output had reached $232 \mathrm{Mt}$, which increased $43.3 \%$ compared with the output of 1980 . However, carbon emissions also increased from $70.7 \mathrm{Mt}$ in 1980 to $226 \mathrm{Mt}$ in 2008 [30]. This shows that between 1980 and 2012, the TNP experienced huge carbon emissions increases.

Therefore, the TNP was chosen as a case study to establish model of carbon emissions. Moreover, the model can be applied not only to other provinces or districts, but also to other countries. The data used
Table 2. Indirect emission dominance intensity of each sector. Data are dimensionless.

\begin{tabular}{|c|c|c|c|c|}
\hline Province & Sector $^{\mathrm{a}}$ & $\begin{array}{c}\text { Primary } \\
\text { energy }\end{array}$ & $\begin{array}{c}\text { Secondary } \\
\text { energy }\end{array}$ & All energy \\
\hline \multirow{8}{*}{ Liaoning } & A & 0.98 & 0.65 & 0.82 \\
\hline & M & 0.75 & 0.70 & 0.74 \\
\hline & PM & 0.98 & 0.91 & 0.95 \\
\hline & $\mathrm{AM}$ & 0.94 & 0.57 & 0.78 \\
\hline & ET & 0.13 & 0.55 & 0.15 \\
\hline & $\mathrm{C}$ & 0.99 & 0.56 & 0.98 \\
\hline & TI & 0.97 & 0.54 & 0.76 \\
\hline & Total & 0.75 & 0.62 & 0.70 \\
\hline \multirow{8}{*}{ Jilin } & $\mathrm{A}$ & 0.97 & 0.68 & 0.89 \\
\hline & M & 0.71 & 0.58 & 0.07 \\
\hline & PM & 0.90 & 0.96 & 0.91 \\
\hline & $\mathrm{AM}$ & 0.94 & 0.57 & 0.86 \\
\hline & ET & 0.15 & 0.77 & 0.16 \\
\hline & $\mathrm{C}$ & 0.99 & 0.92 & 0.97 \\
\hline & TI & 0.89 & 0.55 & 0.81 \\
\hline & Total & 0.70 & 0.64 & 0.69 \\
\hline \multirow{8}{*}{ Heilongjiang } & A & 0.84 & 0.62 & 0.76 \\
\hline & M & 0.62 & 0.62 & 0.64 \\
\hline & PM & 0.97 & 0.77 & 0.97 \\
\hline & $\mathrm{AM}$ & 0.71 & 0.40 & 0.69 \\
\hline & ET & 0.10 & 0.46 & 0.12 \\
\hline & $\mathrm{C}$ & 1.00 & 0.99 & 1.00 \\
\hline & TI & 0.83 & 0.48 & 0.78 \\
\hline & Total & 0.58 & 0.56 & 0.57 \\
\hline Total & & 0.70 & 0.62 & 0.67 \\
\hline
\end{tabular}

${ }^{a}$ Sector names are defined in Table1.

are from Three Northeastern Provinces Statistical Yearbook, 2012. [28].

\section{Results}

\section{Robustness Analysis}

The curve presented in Fig. 2 divides the indicator points into left and right parts. If the indicator is on the left of the curve, the carbon emissions system inclines to more capacity and less ascendency. If the indicator lies on the right of the curve, the system is fragile but more efficient. As shown in Fig. 2, the three points in the curve are closely adjacent, indicating that the primary energy has the highest robustness, with capacity and redundancy values of 0.26 and 0.15 , respectively. 
The robustness value of all energy is almost equal to that of primary energy. The secondary energy has the minimum robustness value, with capacity and redundancy values of 0.24 and 0.15 , respectively, which are similar to those of all energy and primary energy. Overall, the robustness values of all energy and primary energy are higher than that of secondary energy, suggesting that carbon emissions from all energy and primary energy could be controlled easily through policy improvements and adjustments of intersectoral flows.

\section{Direct and Indirect Analysis}

Fig. 3 shows the carbon emissions of the 21 sectors in the TNP. The three sub-figures from left to right (i.e., Fig. 3 (a1), (a2) and (a3)) reflect the carbon emissions of different provinces at the same energy type level. And the top-down three sub-figures (i.e., Fig. 3 (a1), (b1) and (c1)) indicate the carbon emissions from the use of different energy types in the same province. When considering the same energy type (Fig. 3(a1-a3)), the direct and indirect emissions of all energy type in the TNP are 923 and $1897 \mathrm{Mt}$, respectively. In terms of the direct carbon emissions, the ET sector has the maximum emissions (457 Mt), which accounts for $49.5 \%$, followed by the AM sector $(283 \mathrm{Mt})$ and the TI sector $(99.0 \mathrm{Mt})$. In contrast, the direct carbon emissions are highest in the AM sector $(919 \mathrm{Mt})$ followed by the TI sector $(315$
Mt), accounting for $48.5 \%$ and $16.6 \%$ of total emissions, respectively. Moreover, the indirect emissions were almost double the direct emissions in the all energy group, indicating the importance of indirect emissions study. The indirect emissions are the main source of carbon emissions in the all energy group, accounting for $67.2 \%$ of total emissions. The result for the primary energy group is almost the same as that of the all energy group. In Fig. 3(b1-b3), the highest direct and indirect emissions are found in the ET sector (448 Mt) and AM sector (655 Mt), respectively. In Fig. 3(c1-c3), the direct and indirect emissions are the highest in the AM sector, indicating that the AM sector is the main source of emissions from the secondary energy group.

When considering different energy types, as shown in Fig. 3(a1), (b1) and (c1), the indirect emissions of Liaoning province (2119 MT) are more than double its direct emissions (891 Mt). For indirect emissions, the sector with the largest emissions is the AM sector (1193 Mt), followed by the TI sector (285 Mt) and the C sector $(199 \mathrm{Mt})$. These three sectors account for $79.1 \%$ of the total indirect emissions of Liaoning province. For indirect emissions, the ET sector has the highest indirect emissions (393 Mt), followed by the AM sector (336 Mt). When the emission type is not considered, the largest emissions are clearly from the AM sector (1530 Mt), accounting for $50.8 \%$ of the total emissions (3010 Mt). The same phenomenon is found in Jilin province and Heilongjiang province, which reflects that
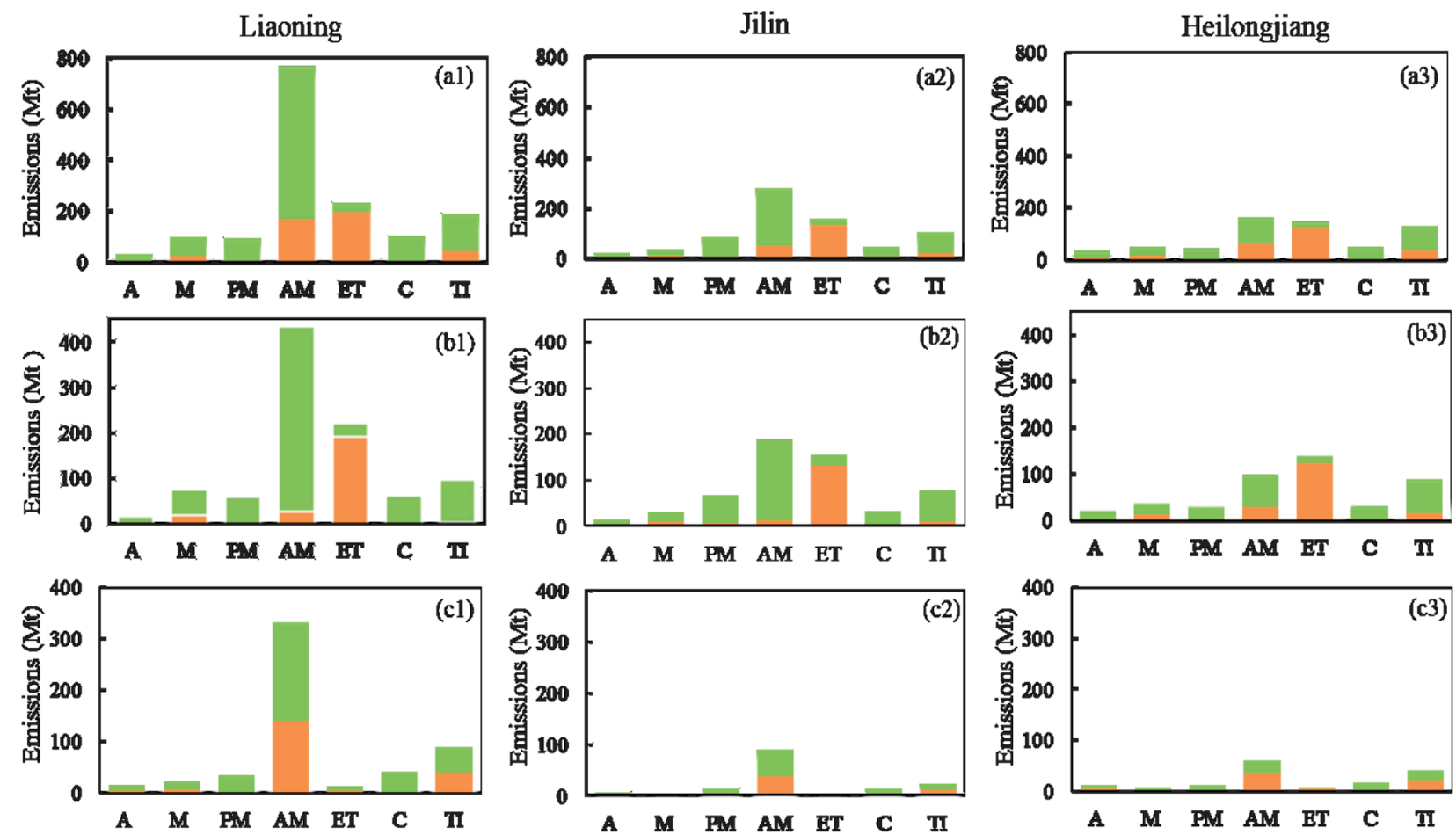

Fig. 3. Direct and indirect carbon emissions of each sector for all energy (a1-a3), primary energy (b1-b3) and secondary energy (c1c3). a1-c1 present carbon emissions in Liaoning province, a2-c3 present carbon emissions in Jilin province and a3-c3 present carbon emissions in Heilongjiang province. Orange represents direct emissions and green represents indirect emissions. Sector names (x axis) are defined in Table 1. 
the AM sector has the largest amount of emissions in all sectors.

Overall, indirect emissions are clearly much higher than direct emissions. The AM sector has the largest carbon emissions, while the A sector has the smallest emissions. The emissions of the manufacturing industry are far greater than other sectors. In addition, the $\mathrm{C}$ sector has almost no direct carbon emissions, and the ET sector has almost no indirect carbon emissions.

The IE-DIT represents the significance of indirect emissions in different sectors of different provinces (Table 2). If the value of indirect dominance is high, the sector is dominated by indirect emissions. For example, in the primary energy group of Liaoning province, the value of the IE-DIT of ET sector is 0.13 , which reflects that the direct emissions are the main type of carbon emissions. In Jilin province, the value of IE-DIT in primary energy group $(0.15)$ is low, whereas that in the secondary energy group (0.77) is higher, indicating that the lower IE-DIT value of all energy group is caused by secondary energy sources. Therefore, it is necessary for the ET sector to promote the use of primary energy. The same phenomenon is found in Jilin province and Heilongjiang province. Conversely, it should also be noted that the IE-DIT values of the $\mathrm{C}$ sector in the all energy group (0.98) and the primary energy group (0.99) of Liaoning province are close to 1.0, but the value in the secondary energy group is only 0.56 , indicating that the indirect emissions of secondary energy sources has little impact on that of the all energy group. Overall, the IE-DIT value of indirect emissions in all provinces is high, which reflects the indirect emissions are far more than direct emissions. Therefore, inter-sectoral flows need to be coordinated to increase direct emissions.

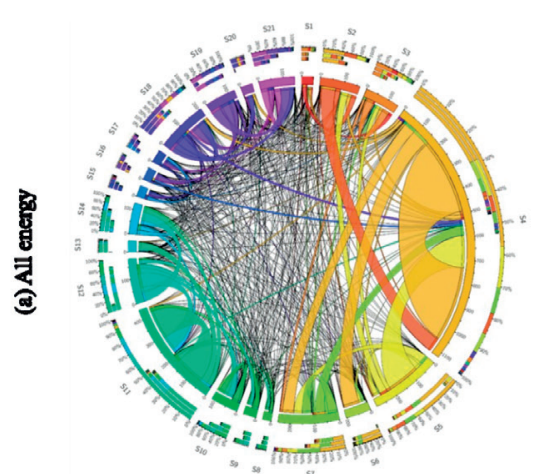

(a1)

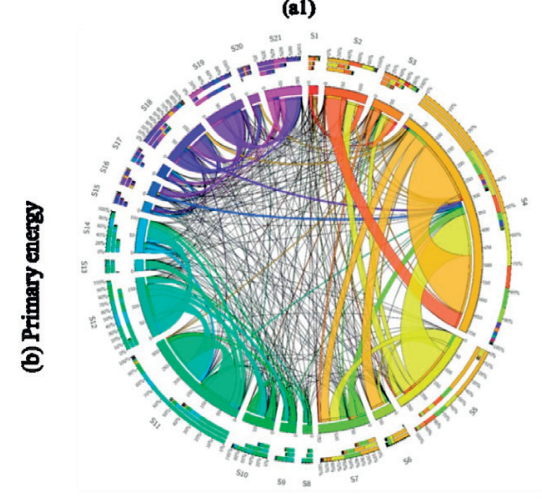

(b)

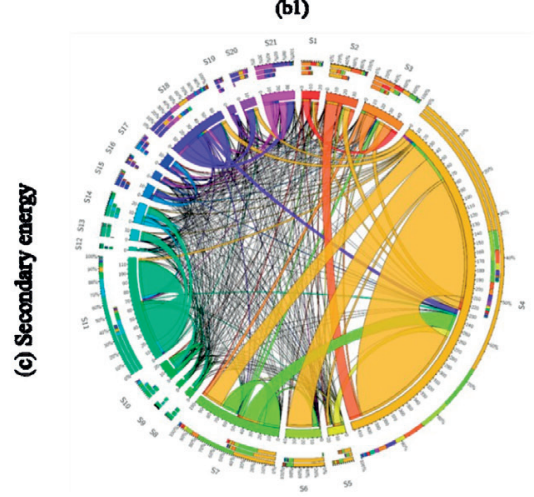

(c1)

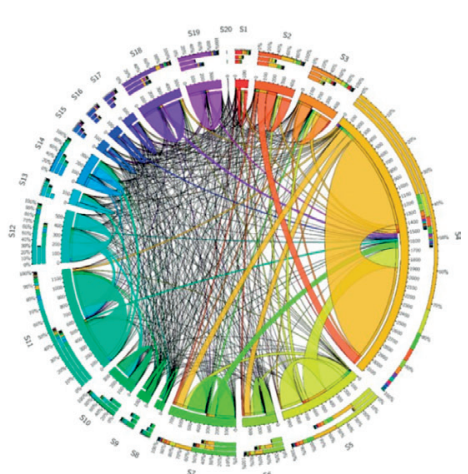

(a2)

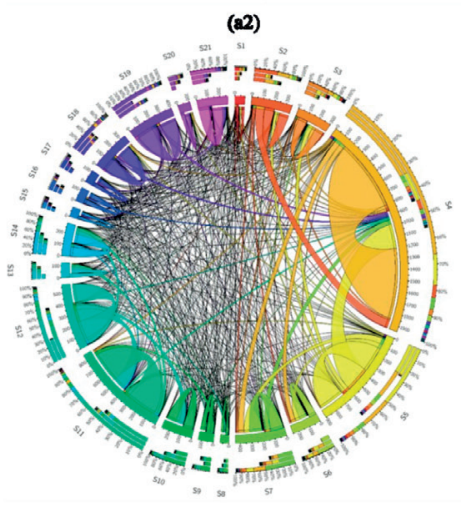

(b2)

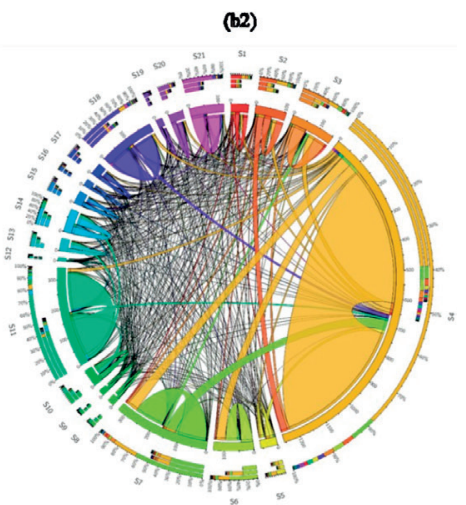

(2)

Fig. 4. Direct and indirect carbon flows of each sector in all energy (a), primary energy (b) and secondary energy (c). a1-c1 show the direct carbon flow, and a2-c2 show the indirect carbon flow. S1-S7 represent the seven sectors in Liaoning province, S8-S14 represent the seven sectors in Jilin province, S15-S21 represent the seven sectors in Heilongjiang province. Sector names are defined in Table 1. 
Fig. 4 shows the direct and indirect carbon flows in different provinces and sectors. The figures are divided into three colors, orange, green and purple. The difference of colors reflects different provinces and sectors. The orange part (S1-S7) represents carbon flows of seven sectors (A, M, PM, AM, ET, C, TI) in Liaoning province, green (S8-S14) represents seven sectors of Jilin province carbon flows and purple (S15-S21) reflects Heilongjiang province. The color of line represents the color of the initial sector. The width of streamline between sectors reflects the amount of carbon flow, indicating the carbon flows between this sector and other sectors. In Fig. 4 (a1) (a2), the direct carbon flow from the AM sector to the ET sector (S4S5) are much higher than indirect flows, which may be due to differences in trade activities between the two sectors. In addition, carbon flows are concentrated in sectors of a province, and the flows between different sectors of the three provinces are negligible.

There is little difference between direct carbon flow and indirect carbon flow. The carbon flow (including carbon inflow and carbon outflow) in Liaoning province is greater than that in Jilin and Heilongjiang provinces. Moreover, the direct flow is larger than the indirect flow The AM sector discharges the most carbon to other sectors or provinces (especially to Liaoning province). Furthermore, in TNP, the AM sector has the largest carbon flow in Liaoning province, indicating that the AM sector of Liaoning province has caused more carbon flow in TNP.

\section{Network Utility Analysis}

The relationships among the different sectors are shown in Fig. 5, which reveals 210 pairs of relationships within the 21 sectors. The relationships include three types: mutualism, competition and exploitation (excluding the relationship with the same sector).

In Fig. 5, different grids have different colors representing the different relationships between two sectors. The bright colors reflect positive values and the dark colors reflect negative values. The relationships of two sectors can be determined form using the rule of diagonal symmetry to connect two grids. Exploitation relationships dominate in the three energy groups, accounting for $48.0 \%, 51.0 \%$ and $60.0 \%$ of total relationships, respectively. The proportion of competition relationships is $28 \%$ for all three energy groups. Mutualism relationships account for $24.0 \%$, $21.0 \%$ and $12.0 \%$ of total relationships, respectively.

Observing the entire system, the relationships between sectors in a province is complex, but the relationships between sectors in different provinces are weak. For example, in Fig. 5a), the grids of line 5 (ET1, column 1 to 7), line 12 (ET2, column 8 to 14), line 19 (ET3, column 15 to 21) have red colors, whereas the grids in the same line but different columns have almost light colors or no color. This reflects that the trade flows of the ET sector and other sectors are mainly concentrated in the inner-province, and the carbon emissions output of the ET sector to the others are higher than the input from other sectors to the ET a) All energy

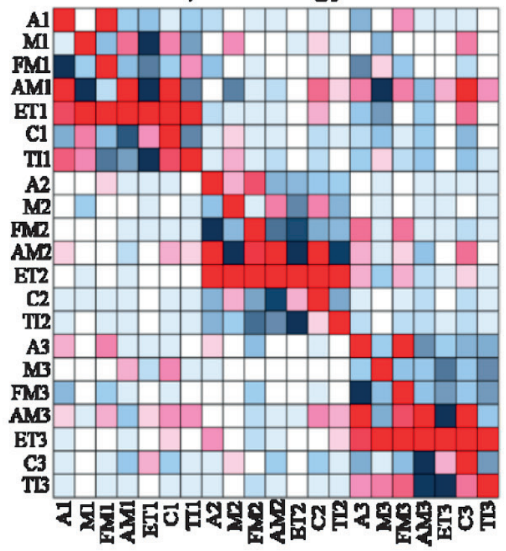

NSI $=19.22$ PNR $=0.99$

$\mathrm{MR}=0.24 \mathrm{ER}=0.48 \mathrm{CR}=0.28$ b) Primary energy

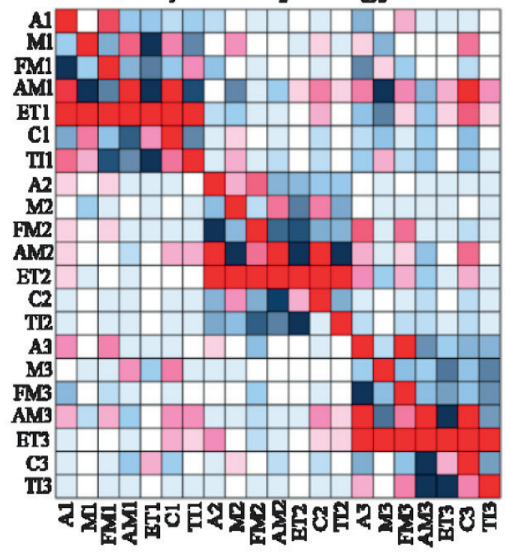

NSI $=20.14$ PNR $=0.97$

$\mathrm{MR}=0.21 \mathrm{ER}=0.51 \mathrm{CR}=0.28$ c) Secondary energy

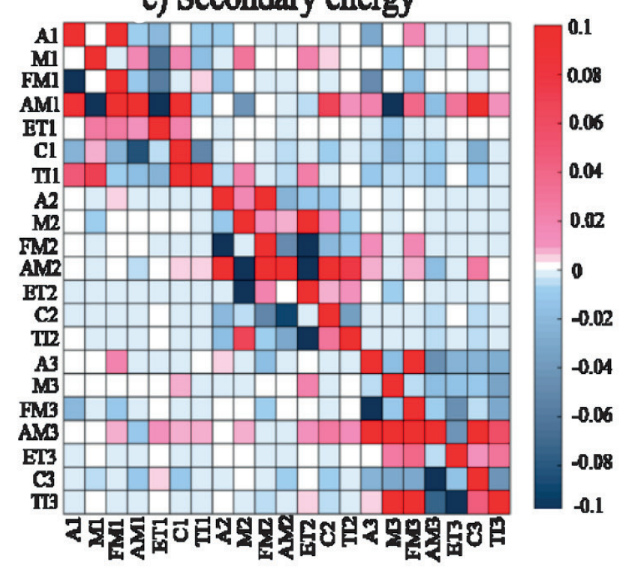

$\mathrm{NSI}=21.04 \mathrm{PNR}=0.81$ $\mathrm{MR}=0.12 \mathrm{ER}=0.60 \mathrm{CR}=0.28$

Fig. 5. Emission relationships of the 21 sectors in all energy a), primary energy b) and secondary energy c). The bright colors reflect positive values and the dark colors reflect negative values. The relationships of two sectors can be determined based on using the rule of diagonal symmetry to connect the two grids. A1-TI1 represent sectors of Liaoning province, A2-TI2 represent sectors of Jilin province, A3-TI3 represents sectors of Heilongjiang province. Sector names are defined in Table 1. The network synergism index (NSI) is the summation of the values of matrix U. The positive negative ratio (PNR) is the ratio of the number of positive signs over the number of negative signs in matrix $U$. The mutualism relationship ratio (MR) is the ratio of the number of pairwise mutualism relationships. The competition relationship ratio $(\mathrm{CR})$ is the ratio of the number of pairwise competition relationships. The exploitation relationship ratio (ER) is the ratio of the number of pairwise exploitation relationships. Sector names are defined in Table 1. 
sector. In contrast, the FM1 sector is controlled by the other sectors and has a negative impact on others. Moreover, tracing each sector's carbon emission sources could help adjust its trade flows to achieve emission reduction targets.

A mutualism relationship reveals a meaningful way to reduce carbon emissions. For example, there is a positive correlation between the ET and $\mathrm{M}$ sectors in Liaoning province. This indicates that once the emissions of the $\mathrm{M}$ sector are reduced, the carbon emissions of the ET sector will also decrease. Moreover, the inner trade flows of a sector always generate maximum profits for that sector ( e.g. Fig.5a)).
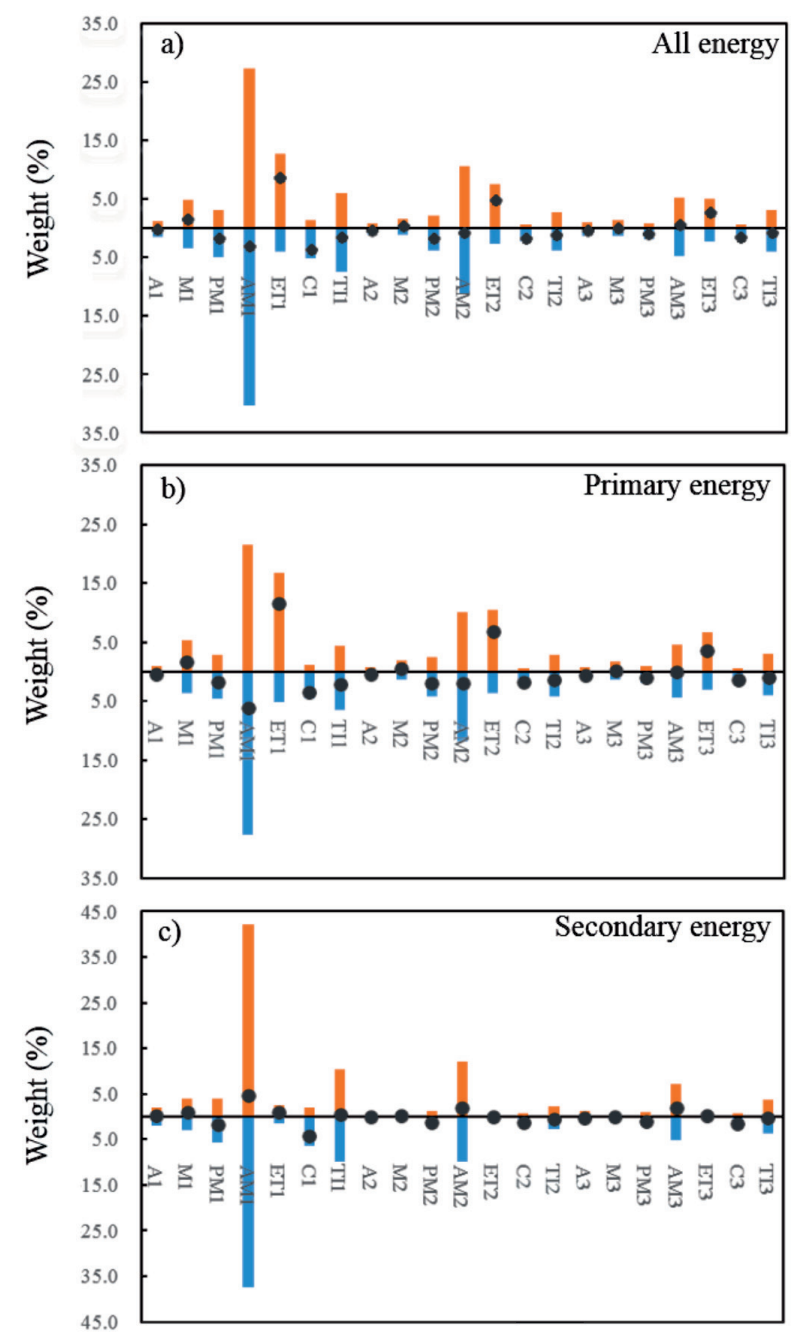

Fig. 6. The degree of control and dependence of each sector in all energy a), primary energy b) and secondary energy c). The orange column reflects the driving force that means the ability of the sector to control the downstream sectors. The blue column represents the pulling force. The total weight is shown in the black point. The point is distributed on both sides of the horizontal axis. If above the horizontal axis, it represents the driving force is dominant. Below the horizontal axis shows that the pulling force is dominant. A1-TI1 represent sectors of Liaoning province, A2-TI2 represent sectors of Jilin province, and A3-TI3 represent sectors of Heilongjiang province. Sector names are defined in Table 1
A competition relationship indicates that one sector is harmful to another sector in trade flows. However, when considering carbon emissions, this relationship represents good interactions. For example, the $\mathrm{C}$ and A sectors of all energy in Jilin province show a competition relationship $(-0.01,-0.02)$ revealing that the more interactions there are between the two sectors, the less carbon emissions result. Therefore, increasing competition relationships between sectors has the potential to greatly decrease carbon emissions.

In addition, the NSI $>0$ reveals that the sum of positive quantity is greater than negative quantity and the system is a symbiotic state. The PNR (the value is close to 1$)<1$ indicates that the number of the negative value is slightly higher than the positive value and the carbon emission system is stable.

\section{Network Control Analysis}

The pulling force weight and driving force weight, which represent the degree of demand and the degree of control, are shown in Fig. 6. The orange column reflects the driving force that means the ability of the sector to control the downstream sectors. The blue column represents the pulling force, which shows that the degree of dependence of the sector to upstream sectors. And the total weight is shown in the black point. The point is distributed on both sides of the horizontal axis. If above the horizontal axis, it represents the driving force is dominant. However, below the horizontal axis shows that the pulling force is first ruler and needs the upstream sectors to maintain stability.

Fig. 6a) clearly shows that the driving force of the AM sector is the biggest for all energy, followed by that of the ET and TI sectors, which suggests that these sectors have strong control force to the downstream sectors. These sectors also have the highest pulling force, indicating the importance of these sectors for adjusting the carbon balance in the all energy group. However, the black points of the AM, TI and C sectors appear below the horizontal axis, indicating that the effect of the pulling force of these sectors is stronger than the driving force. In contrast, in the secondary energy group (Fig. 6c)), although the pulling force and driving force of the AM sector remains the highest, the black point appears above the horizontal axis, indicating that the AM sector can strongly influence the secondary energy system by controlling supply to downstream sectors.

\section{Discussion}

The carbon emissions, carbon flows and the stability of the system among sectors and provinces were studied in our research from the perspective of input-output analysis and ecological network analysis.

The significance of indirect carbon emissions and flow are often ignored in other studies. Taking the 
TNP as an example, indirect flow and emissions were emphasized in our research. The results show that the indirect emissions of the system are two times larger than the direct emissions. The AM sector, which is the pillar sector of TNP, has the highest indirect emissions. This is because the AM sector mainly relies on other sectors' materials or products to create economic benefits, so as to indirectly emit a large amount of carbon. This demonstrates that the relevant sectors should formulate policies to reduce indirect emissions. In addition, the indirect carbon flows are caused by the complex network system. The direct flow could reflect the direct emission relationships between sectors, and the indirect flow could reflect the hidden relationships between sectors. The importance and complexity of the indirect flow far exceeds our expectations, but are often overlooked. Analysis of indirect flow reveals meaningful findings, for example, metal products are the best material for manufacture of equipment, and chemical products are excellent material for manufacture of textiles, which results in the highest indirect carbon flows within the AM sector and from the AM sector to the PM sector. Therefore, to attain carbon flow balance, intersectoral relations need to be well coordinated. Furthermore, the secondary industry is the dominant industry that should be changed, and the proportion of the tertiary industry in the entire industrial structure should be increased.

The ENA method was further developed to analyze the complex relationships within the carbon emission and flow in the TNP. The NCA results show that most sectors have stronger driving forces and weaker pulling forces, which indicates that most sectors have a strong ability to control the downstream sectors. Different types of sectors have different force, for example, the AM sector has a stronger driving force and pulling force, whereas the $\mathrm{A}$ and $\mathrm{M}$ sectors both have weak driving forces and pulling forces, indicating that the AM sector plays an important role in adjusting carbon balance of the TNP. Furthermore, analysis of the distribution of controllers and dependents could provide effective suggestions for intersectoral communications and emission reductions. For controllers, such suggestions could be provided from the production side. In contrast, for sectors that depend on other sectors, the advice should be given from the consumption side.

The results of NUA reveal deep intersectoral relationships. In the entire system, the mutualism relationship is dominant, which reflects that the system is in a symbiotic state. However, this is an unsatisfactory result for carbon emission reductions because the two sectors that have mutualism relationships have greater cooperation and will discharge more emissions. The best relationship in terms of carbon emission reductions is a competitive relationship. For example, the utility relationship between the $\mathrm{C}$ and $\mathrm{A}$ sectors under the all energy group in Jilin province is a competitive relationship. This means the two sectors will compete, which may limit the development from both sides, so carbon emissions of these two sectors will be reduced simultaneously. However, increases to competition relationships will restrict the sector development. How to coordinate the relationships within the system is paramount. Generally, there are many difficulties involved in changing the ecological relationship between sectors, which may influence the economic development of the region in the future.

The stability of the system was analyzed based on robustness results. The three points from the robustness curve are all on the left of the curve, which shows that there are many emissions pathway for carbon emission system of the TNP, and the system has strong force to deal with internal and external changes. Therefore, it is necessary for different industries to formulate different policies or regulations. Moreover, by combining robustness analysis, features from different sectors could be displayed and related solutions could be provided. Overall, the TNP has achieved considerable economic growth, but the carbon emissions have grown substantially at the same time. This may be because coal and crude oil are the main energy consumption types, and consumption of clean energy such as hydropower resources are the least consumed energy types.

Therefore, in order to achieve the aim of emission reduction, we provide some suggestions as follows: the first is to adjust the energy structure as far as possible [29], decreasing the consumption of coal and increasing the consumption of clean energy. Secondly, although the status of major use of coal cannot change, we could improve its energy efficiency. Thirdly, forest area needs to be maximized to absorb carbon.

In this research, there are some limitation on the path of carbon flows is not be shown, which needs to be improved in the future research.

\section{Conclusion}

In this study, the CEIO was used to analyze carbon emissions and flows in the region and sectors of the TNP in China. Moreover, a new factor, IE-DIT, was proposed to compare direct emissions and indirect emissions, and the result shows that the indirect emissions greatly exceeded the direct emissions of the system. As the pillar industry of the TNP, the AM sector promoted the economy and produced high indirect carbon emissions at the same time. The indirect carbon emissions of the AM sector were highest in Liaoning province, which indicates that reducing indirect carbon emissions of the AM sector in Liaoning province is important to reduce indirect carbon emissions in the TNP. Heilongjiang and Jilin provinces, which have lower indirect carbon emissions, should consider how to decrease direct emissions from the different sectors.

In future, the drivers of $\mathrm{CO}_{2}$ emissions in other urban agglomeration should be studied using CEIO model to assist government decision makers in 
formulating emission reduction policies for low-carbon city construction.

\section{Author Contributions}

Jiazheng Sun: designed model, analyzed the data, Writing draft. Hongkuan Zang: Supervision, Funding acquisition. Zhengping Liu: Visualization. Yu Han: Investigation. Xuyu Zhang: Methodology, software.

\section{Acknowledgements}

This research was supported by the National Key R\&D Program of China (grant no. 2018YFC1900104).

\section{Conflicts of Interest}

The authors declare no conflicts of interest.

\section{References}

1. LIU C., WANG T., GUO Q. Factors aggregating ability and the regional differences among china's urban agglomerations. Sustainability, 10, 4179, 2018.

2. THORNTON J.D., SWANSON D.J., MARY M.N., PEI D., MARTIN A.C., POUNDS S., GOLDOWITZ D., SKAPEK S.X. Persistent hyperplastic primary vitreous due to somatic mosaic deletion of the Arf tumor suppressor. Investig. Ophthalmol. Vis. Sci. 48, 491, 2007.

3. YU L., ZHU T., WANG Z., TIAN H. A study on energy consumption and economic growth of three northeastern provinces in China. 2011 Int. Conf. Control. Autom. Syst. Eng. CASE. 2011.

4. WANG Z.Y., MENG J., ZHENG H.R., SHAO S., WANG D.P., MI Z.F., GUAN D.B. Temporal change in India's imbalance of carbon emissions embodied in international trade. Appl. Energy. 231, 914, 2018.

5. ZANG Z., ZOU X.Q., SONG Q.C., WANG T., FU G.H. Analysis of the global carbon dioxide emissions from 2003 to 2015: convergence trends and regional contributions. Carbon Manag. 9, 45, 2018.

6. LI Z.L., SUN L., GENG Y., DONG H.J., REN J.Z., LIU Z., TIAN X., YABAR H., HIGANO Y. Examining industrial structure changes and corresponding carbon emission reduction effect by combining input-output analysis and social network analysis: A comparison study of China and Japan. J. Clean. Prod. 162, 61, 2017.

7. SALMAN M., LONG X.L., DAUDA L., MENSAH C.N., MUHAMMAD S. Different impacts of export and import on carbon emissions across 7 Asian countries: A panel quantile regression approach. Sci. Total Environ. 686, 1019, 2019.

8. WANG Z.H., LIU W.L., YIN J.H. Driving forces of indirect carbon emissions from household consumption in China: an input-output decomposition analysis. Nat. Hazards. 75, 257, 2015.

9. LEONTIEF W. Quantitative input and output relations in the economic system of the United States. Rev Econ Stat. 18, 105, 1936.
10. LI J.S., CHEN B., CHEN G.Q., WEI W.D., WANG X.B., GE J.P., DONG K.Q., XIA H.H., XIA X.H. Tracking mercury emission flows in the global supply chains: A multi-regional input-output analysis. J. Clean. Prod. 140, 1470, 2017.

11. BRIZGA J., FENG K.S., HUBACEK, K. Household carbon footprints in the Baltic States: A global multiregional input-output analysis from 1995 to 2011. Appl. Energy. 189, 780, 2017.

12. LIANG S., STYLIANOU K.S., JOLLIET O., SUPEKAR S., QU S., SKERLOS S.J., XU M. Consumption-based human health impacts of primary $\mathrm{PM}_{25}$ : The hidden burden of international trade. J. Clean. Prod. 167, 133, 2018.

13. HAO Y., ZHANG M.H., ZHANG Y., FU C.L., LU Z.M. Multi-scale analysis of the energy metabolic processes in the Beijing-Tianjin-Hebei (Jing-Jin-Ji) urban agglomeration. Ecol. Modell. 369, 66, 2018.

14. LLORET-CLIMENT M. Systems approach to the concept of mutation. Cybern. Syst. 30, 249, 1999.

15. FATH B.D., PATTEN B.C. Network synergism: Emergence of positive relations in ecological systems. Ecol. Modell. 107, 127, 1998.

16. BORRETT S.R., WHIPPLE S.J., PATTEN B.C., CHRISTIAN R.R. Indirect effects and distributed control in ecosystems: Temporal variation of indirect effects in a seven-compartment model of nitrogen flow in the Neuse River Estuary, USA - Time series analysis. Ecol. Modell. 194, 178, 2006.

17. ZHAI M.Y., HUANG G.H., LIU L.R., ZHENG B.Y., GUAN Y.R. Network analysis of different types of food flows: Establishing the interaction between food flows and economic flows. Resour. Conserv. Recycl. 143, 143, 2019.

18. FANG D., CHEN B. Information-based ecological network analysis for carbon emissions. Appl. Energy. 238, 45, 2019.

19. WANG S., FATH B., CHEN B. Energy-water nexus under energy mix scenarios using input-output and ecological network analyses. Appl. Energy. 233-234, 827, 2019.

20. ZHANG G., HUANG G.H., LIU L.R. NIU G., LI J.Z., MCBEAN E. Ecological network analysis of an urban water metabolic system based on input-output model: A case study of Guangdong, China. Sci. Total Environ. 670, 369, 2019.

21. MEDDEB M., NIQUIL N., GRAMI B., MEJRI K., HARALDSSON M., CHAALALI A., PRINGAULT O., HLAILI A.S. A new type of plankton food web functioning in coastal waters revealed by coupling Monte Carlo Markov chain linear inverse method and ecological network analysis. Ecol. Indic. 104, 67, 2019.

22. MUKHERJEE J., KARAN S., CHAKRABARTY M., BANERJEE A., RAKSHIT N., RAY S. An approach towards quantification of ecosystem trophic status and health through ecological network analysis applied in Hooghly-Matla estuarine system, India. Ecol. Indic. 100, 55, 2019.

23. CHEN X., YU J.H., XUE C.H., WANG Y.M., TANG Q.J., MAO X.Z. Mechanism of neoagarotetraose protects against intense exercise-induced liver injury based on molecular ecological network analysis. Biosci. Biotechnol. Biochem. 83, 1227, 2019.

24. BRIESE E., PIEZER K., CELIK I., APUL D. Ecological network analysis of solar photovoltaic power generation systems. J. Clean. Prod. 223, 368, 2019.

25. ZHAI M.Y., HUANG G.H., LIU L.R., XU X.L., LI J.Z. Transfer of virtual water embodied in food: A new perspective. Sci. Total Environ. 659, 872, 2019. 
26. ZHAI M.Y., HUANG G.H., LIU L.H., SU S. Dynamic input-output analysis for energy metabolism system in the Province of Guangdong, China. J. Clean. Prod. 196, 747, 2018.

27. ZHANG Y., ZHENG H.M., FATH B.D., LIU H., YANG Z.F., LIU G.Y. SU M.R. Ecological network analysis of an urban metabolic system based on input-output tables: Model development and case study for Beijing. Sci. Total Environ. 468-469, 642, 2014.

28. NBS (National Bureau of Statistics of China). China statistical yearbook 2012. China Statistics Press, Beijing 2013 [In Chinese].
29. LI J. Adjust Energy Structure, Promoting Chinese Environmental Protection. Appl. Mech. Mater. 672-674, 2065, 2014.

30. ZHAO J. Carbon emission from three provinces in the northeast of china energy consumption and analysis of influencing factors. Master's Dissertation. Harbin Normal University, Heilongjiang, China. 2015 [In Chinese]. 


\section{Supplementary Material}

\section{An Input-Output Model for Analyzing Carbon Emissions in the Urban Agglomeration of the Three Northeastern Provinces in China}

\section{Results}

The Pulling Force and Driving Force Weights of Different Sectors of Three Northeastern Provinces

Table S1 The pulling force and driving force weights of differentsectors in all energy, primary energy and secondary energy.

\begin{tabular}{|c|c|c|c|c|c|c|}
\hline \multirow[b]{2}{*}{ Sector } & \multicolumn{3}{|c|}{ Pulling force weight (\%) } & \multicolumn{3}{|c|}{ Driving force weight (\%) } \\
\hline & All energy & Primary energy & Secondary energy & All energy & Primary energy & $\begin{array}{c}\text { Secondary } \\
\text { energy }\end{array}$ \\
\hline A1 & 0.014 & 0.012 & 0.019 & 0.012 & 0.009 & 0.020 \\
\hline M1 & 0.034 & 0.036 & 0.028 & 0.049 & 0.053 & 0.039 \\
\hline PM1 & 0.049 & 0.046 & 0.057 & 0.031 & 0.028 & 0.039 \\
\hline AM1 & 0.304 & 0.276 & 0.375 & 0.273 & 0.215 & 0.422 \\
\hline ET1 & 0.040 & 0.051 & 0.014 & 0.127 & 0.167 & 0.024 \\
\hline $\mathrm{C} 1$ & 0.051 & 0.046 & 0.063 & 0.015 & 0.012 & 0.021 \\
\hline TI1 & 0.075 & 0.065 & 0.100 & 0.061 & 0.044 & 0.104 \\
\hline $\mathrm{A} 2$ & 0.010 & 0.011 & 0.008 & 0.008 & 0.008 & 0.008 \\
\hline M2 & 0.011 & 0.013 & 0.005 & 0.016 & 0.019 & 0.007 \\
\hline PM2 & 0.038 & 0.043 & 0.024 & 0.021 & 0.024 & 0.013 \\
\hline AM2 & 0.113 & 0.119 & 0.099 & 0.106 & 0.100 & 0.120 \\
\hline ET2 & 0.027 & 0.036 & 0.003 & 0.076 & 0.104 & 0.004 \\
\hline $\mathrm{C} 2$ & 0.022 & 0.023 & 0.019 & 0.006 & 0.006 & 0.006 \\
\hline TI2 & 0.038 & 0.043 & 0.026 & 0.027 & 0.029 & 0.022 \\
\hline $\mathrm{A} 3$ & 0.014 & 0.013 & 0.015 & 0.009 & 0.008 & 0.013 \\
\hline M3 & 0.012 & 0.014 & 0.008 & 0.014 & 0.016 & 0.007 \\
\hline PM3 & 0.018 & 0.019 & 0.018 & 0.009 & 0.009 & 0.009 \\
\hline AM3 & 0.047 & 0.045 & 0.053 & 0.053 & 0.045 & 0.072 \\
\hline ET3 & 0.023 & 0.030 & 0.006 & 0.050 & 0.067 & 0.008 \\
\hline $\mathrm{C} 3$ & 0.021 & 0.020 & 0.024 & 0.007 & 0.006 & 0.008 \\
\hline TI3 & 0.039 & 0.040 & 0.038 & 0.031 & 0.030 & 0.036 \\
\hline
\end{tabular}

${ }^{\mathrm{a}} \mathrm{A} 1-\mathrm{TI} 1$ represent sectors of Liaoning province, A2-TI2 represent sectors of Jilin province, and A3-TI3 represent sectors of Heilongjiang province. Sector names are defined in Table 1. 
The sgn(U) values for Three Northeastern Provinces' carbon emissions system.

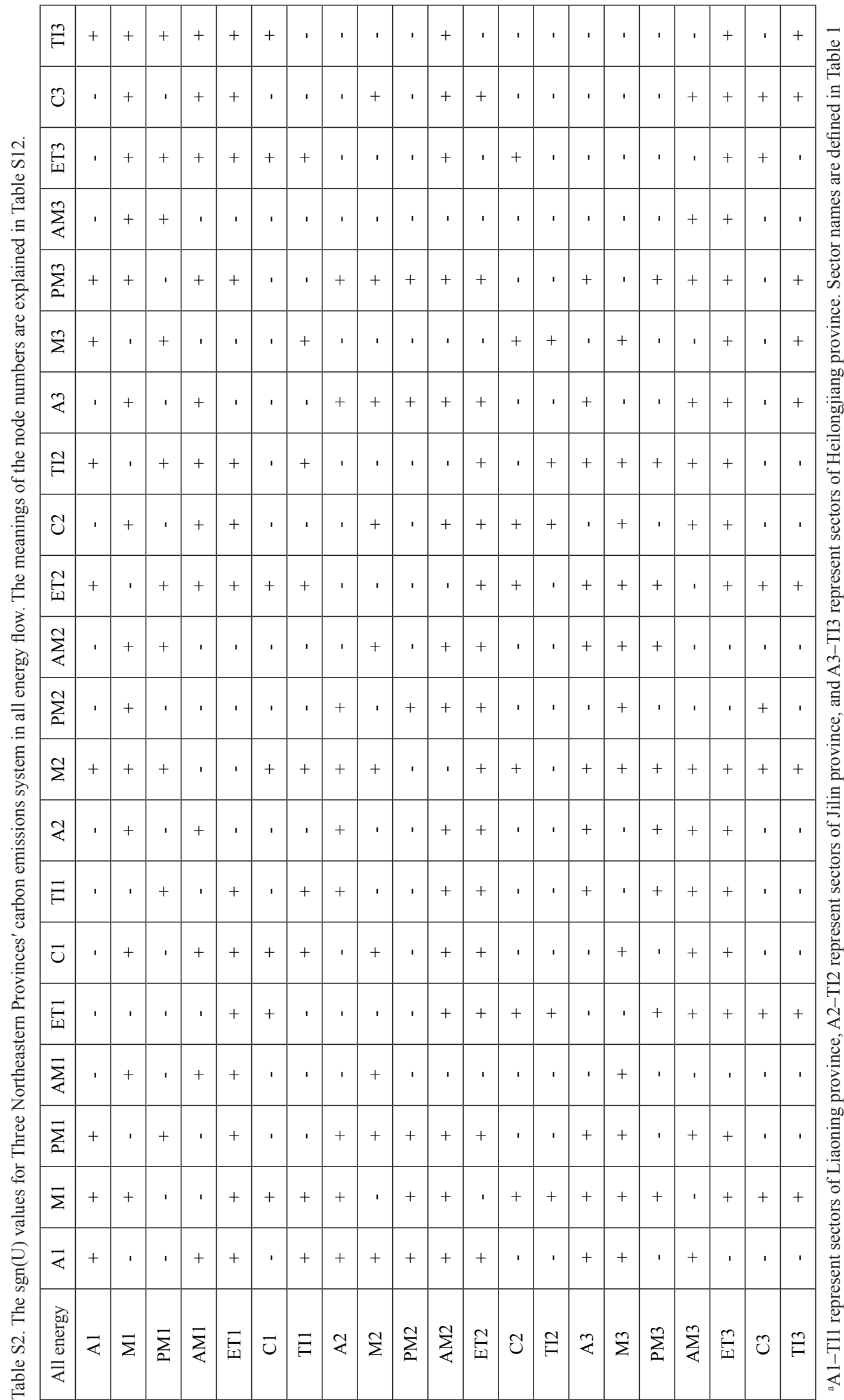




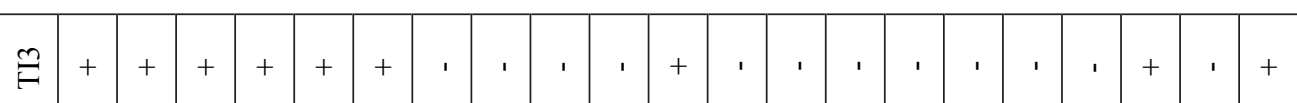

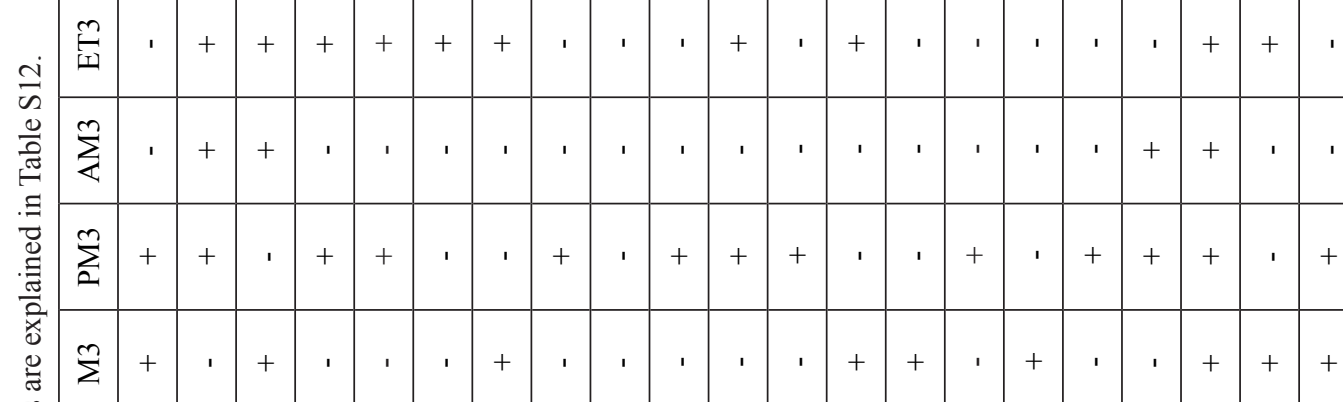
$\frac{\overrightarrow{0}}{\frac{0}{\omega}}$

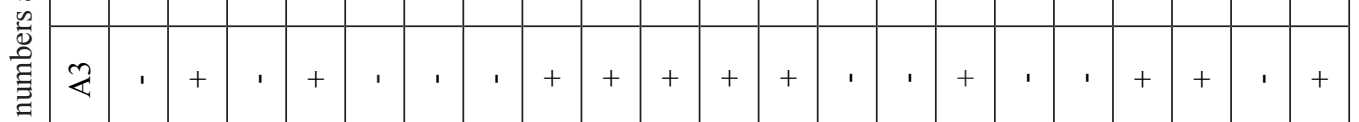

$\stackrel{\square}{\circ}$

荧

刍

离

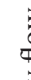

离

这

.

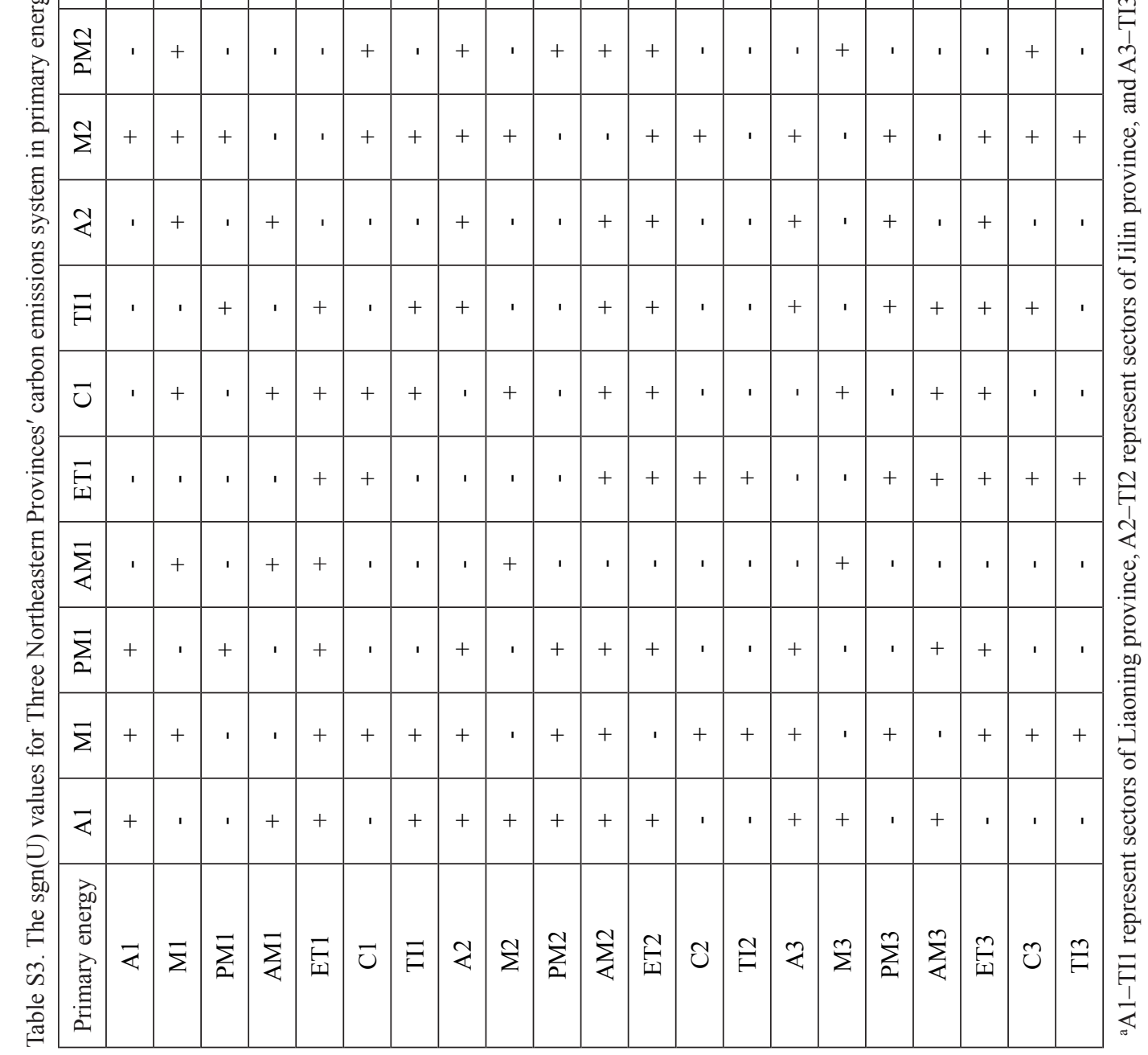




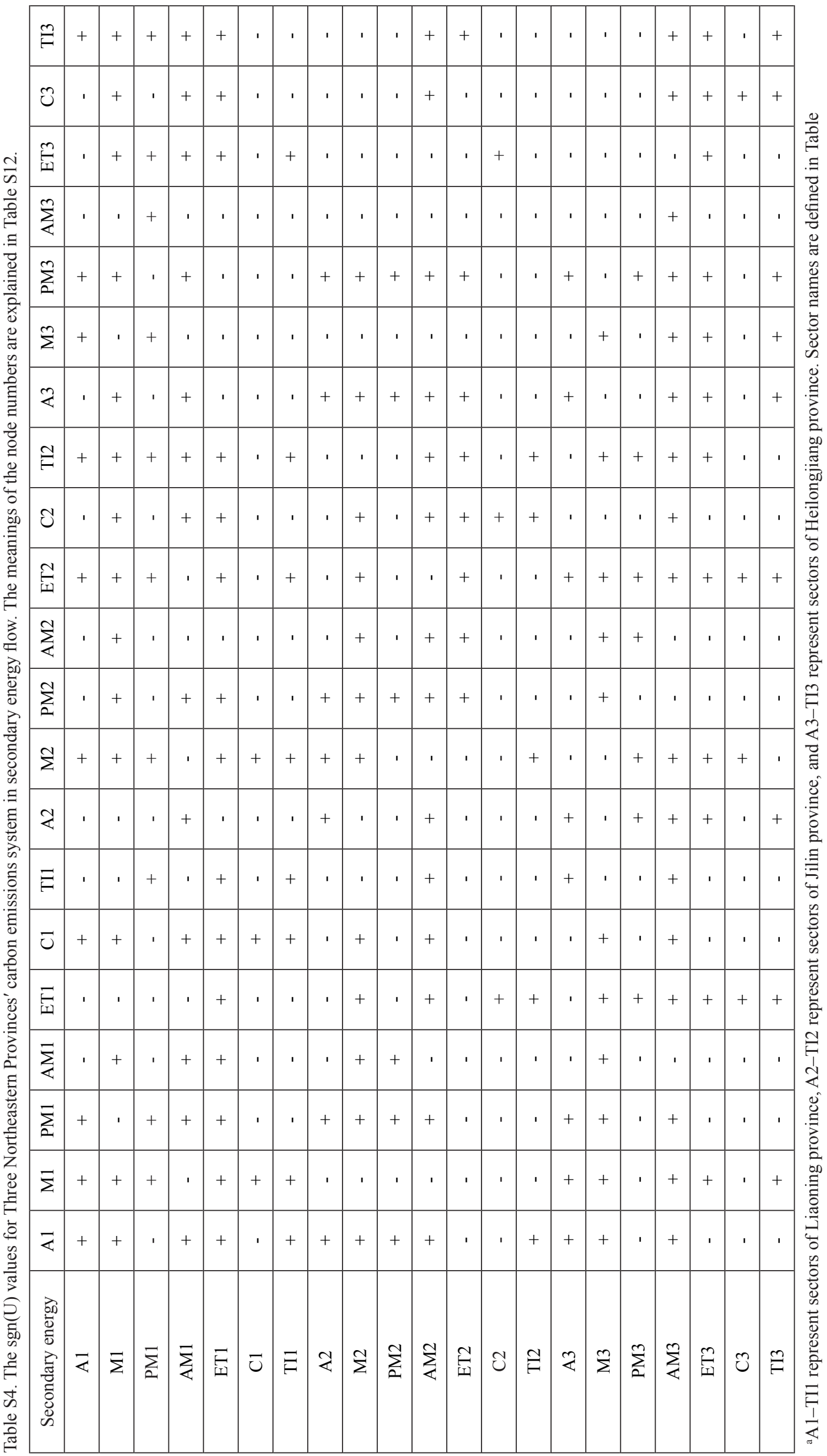


The Direct and Indirect Carbon Flows of Each Sector in All Energy,

Primary Energy and Secondary Energy

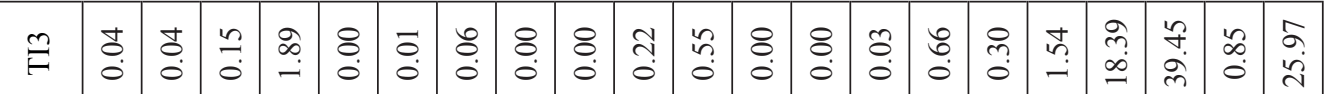

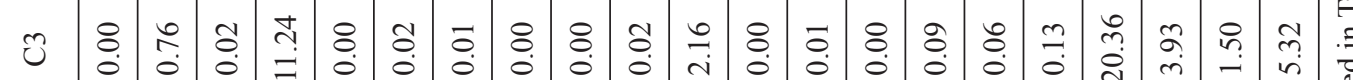

m

島

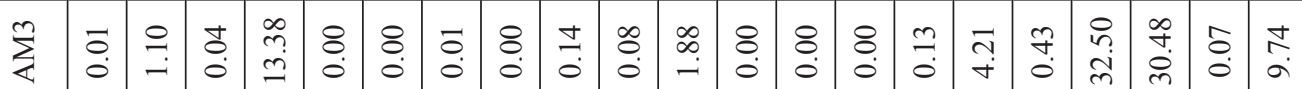

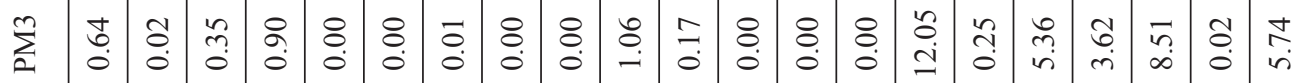

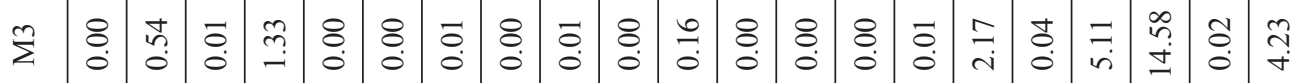

そ)

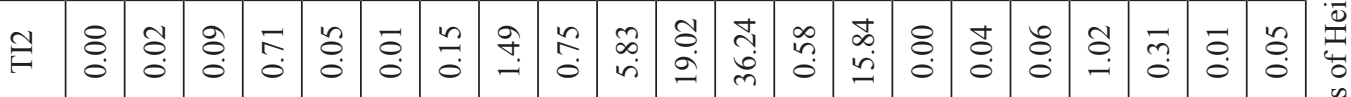

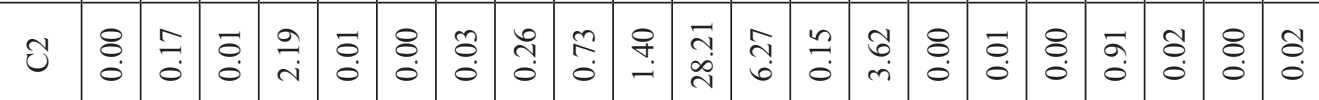

I

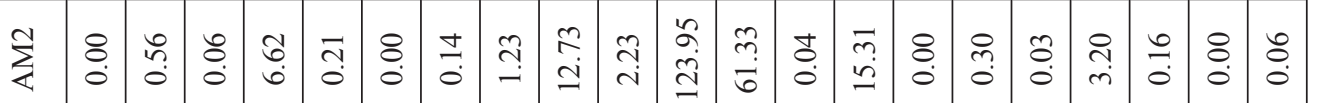

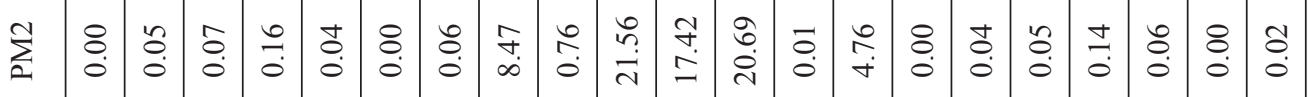

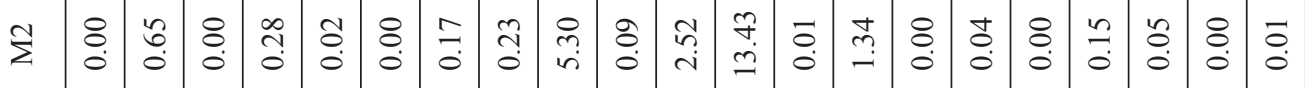

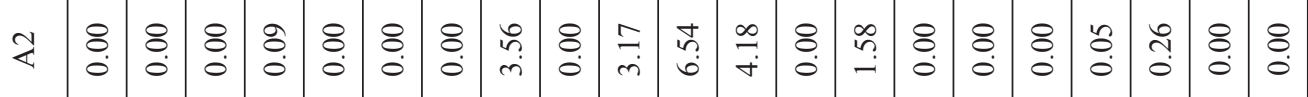

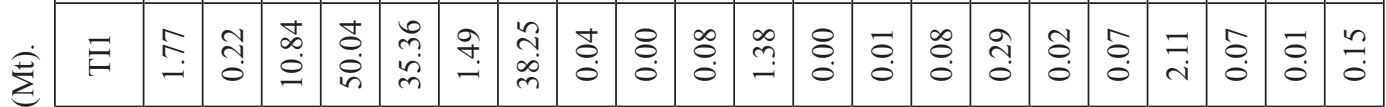

\begin{tabular}{|c|c|c|c|c|c|c|c|c|c|c|c|c|c|c|c|c|c|c|c|c|c|c|}
\hline $\bar{U}$ & $\hat{n}$ & $\stackrel{g}{g}$ & $\stackrel{\infty}{\stackrel{\infty}{\rightarrow}}$ & $\begin{array}{l}\text { ํ. } \\
\text { ò }\end{array}$ & $\stackrel{7}{9}$ & $\stackrel{\infty}{\stackrel{\leftrightarrow}{-}}$ & 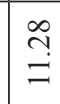 & $\stackrel{\square}{\circ}$ & $\stackrel{8}{\circ}$ & $\stackrel{\overrightarrow{0}}{\circ}$ & $\stackrel{ \pm}{\Xi}$ & 8 & 8 & 8 & : & $\stackrel{n}{=}$ & $\stackrel{8}{0}$ & I & $\stackrel{\leftrightarrow}{0}$ & 8 & $\tilde{O}$ & \\
\hline$\vec{E}$ & $\stackrel{8}{\circ}$ & $\stackrel{?}{\stackrel{r}{r}}$ & $\overrightarrow{\widetilde{\sigma}}$ & $\stackrel{尺}{8}$ & $\begin{array}{l}\text { ț } \\
\stackrel{\sim}{\sim}\end{array}$ & $\stackrel{7}{\circ}$ & $\stackrel{m}{m}$ & $\stackrel{8}{\circ}$ & ठै. & $\stackrel{8}{\circ}$ & 官. & 8 & 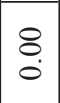 & 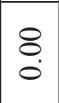 & $\stackrel{8}{0}$ & 苞 & $\stackrel{8}{\circ}$ & $\stackrel{\overbrace{}}{0}$ & $\stackrel{d}{0}$ & $\stackrel{8}{\circ}$ & $\stackrel{\overrightarrow{0}}{0}$ & \\
\hline$\sum$ & \&. & $\begin{array}{l}\infty \\
\infty \\
\text { in }\end{array}$ & in & $\begin{array}{l}\mathcal{U} \\
\text { ¿ें } \\
\text { }\end{array}$ & $\mid \begin{array}{l}\hat{\alpha} \\
\infty \\
0 \\
\end{array}$ & $\begin{array}{l}+ \\
\stackrel{\infty}{0} \\
0\end{array}$ & $\stackrel{\text { I }}{\stackrel{+}{+}}$ & $\stackrel{0}{0}$ & $\underset{i}{ \pm}$ & ô. & $\begin{array}{l}\infty \\
\text { î } \\
\text { in }\end{array}$ & $\stackrel{8}{0}$ & 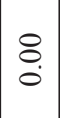 & $\underline{o}$ & $\frac{n}{0}$ & $\frac{m}{a}$ & $\stackrel{\leftrightarrow}{\mathscr{O}}$ & $\stackrel{\varrho}{=}$ & స઼. & 8 & $=$ & \\
\hline$\sum_{i}$ & $\stackrel{n}{m}$ & : & $\begin{array}{l}\tilde{D} \\
\infty \\
\grave{\lambda}\end{array}$ & $\begin{array}{l}n \\
n \\
n \\
n\end{array}$ & 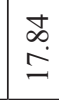 & $\frac{n}{0}$ & $\stackrel{7}{\rightarrow}$ & $\begin{array}{l}\infty \\
\stackrel{\infty}{0} \\
0\end{array}$ & $\stackrel{8}{\circ}$ & $\stackrel{\infty}{0}$ & ָ̊ & 8 & 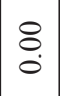 & $\overrightarrow{0}$ & $\underset{i}{i}$ & $\stackrel{8}{0}$ & $\stackrel{d}{\Im}$ & $\stackrel{?}{\Im}$ & $\stackrel{\leftrightarrow}{\circ}$ & $\stackrel{8}{\circ}$ & Oे. & \\
\hline $\bar{\Sigma}$ & : & $\stackrel{\vec{N}}{\stackrel{\sim}{N}}$ & 官 & $\begin{array}{l}8 \\
0 \\
i\end{array}$ & $\begin{array}{l}\stackrel{\sim}{\sim} \\
\stackrel{\text { ते }}{ }\end{array}$ & $\stackrel{\leftrightarrow}{\circ}$ & $\vec{\sim}$ & $\stackrel{8}{\circ}$ & $\stackrel{\overrightarrow{0}}{0}$ & $\stackrel{8}{\circ}$ & $\overrightarrow{\widetilde{o}}$ & 8 & 8 & 8 & $\ddot{\sigma}$ & $\overrightarrow{\widetilde{I}}$ & 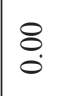 & $\begin{array}{l}1 \\
0 \\
0\end{array}$ & $\stackrel{8}{\circ}$ & $\stackrel{8}{0}$ & : & \\
\hline Z & $\stackrel{?}{+}$ & o. & तิ & o. & $\tilde{\dot{m}}$ & 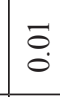 & $\underset{m}{\stackrel{0}{m}}$ & $\overrightarrow{0}$ & $\stackrel{8}{0}$ & $=$ & 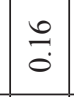 & 8 & $\begin{array}{l}8 \\
0 \\
0\end{array}$ & $\stackrel{8}{0}$ & $\vec{i}$ & $\ddot{0}$ & $\stackrel{8}{\circ}$ & $\stackrel{\tilde{丶}}{0}$ & $\stackrel{\circ}{\circ}$ & $\stackrel{8}{\circ}$ & $\stackrel{\circ}{\circ}$ & \\
\hline 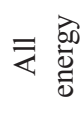 & \& & $\bar{\Sigma}$ & $\sum_{i}$ & $\sum$ & $\vec{E}$ & $\vec{U}$ & $\Xi$ & z & $\Sigma$ & $\sum_{i}^{N}$ & $\sum_{4}^{\pi}$ & $\stackrel{F}{I}$ & $\widetilde{U}$ & $\stackrel{\vartheta}{\vartheta}$ & 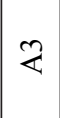 & $\tilde{\Sigma}$ & $\sum_{i}^{m}$ & $\sum_{<}^{n}$ & $\stackrel{P}{+}$ & $\tilde{O}$ & $\stackrel{\vartheta}{F}$ & \\
\hline
\end{tabular}




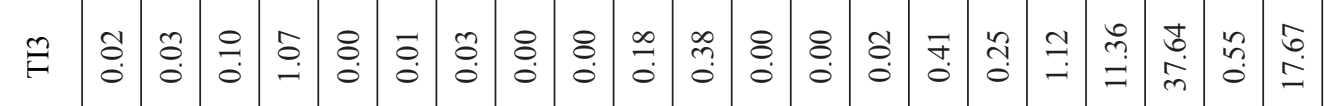

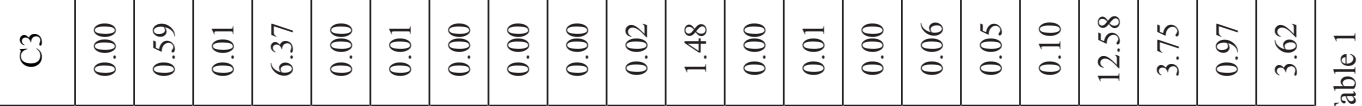

岑

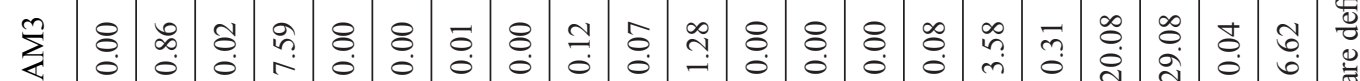

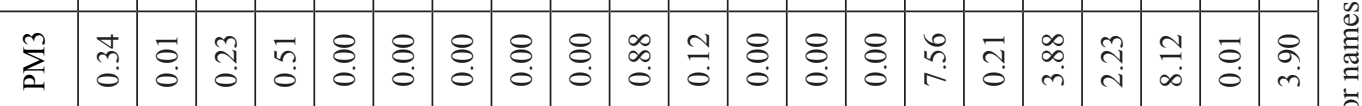

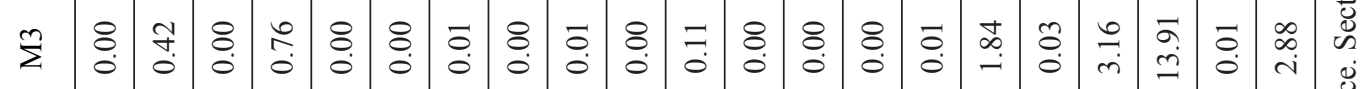

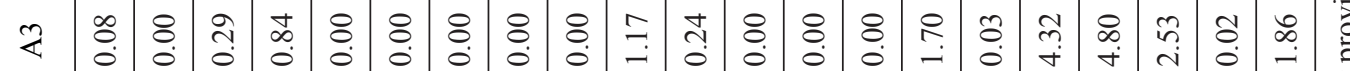

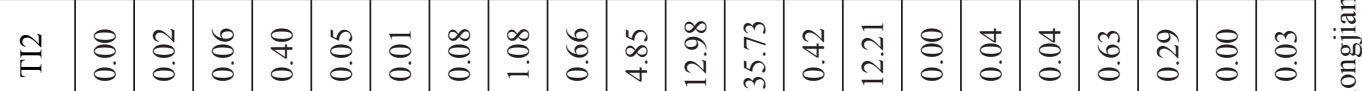

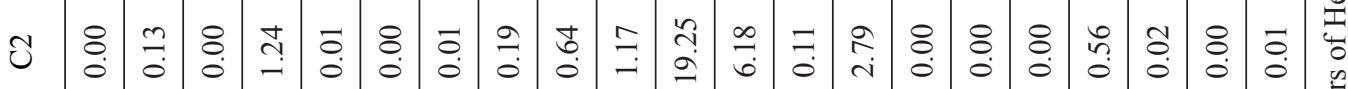

F

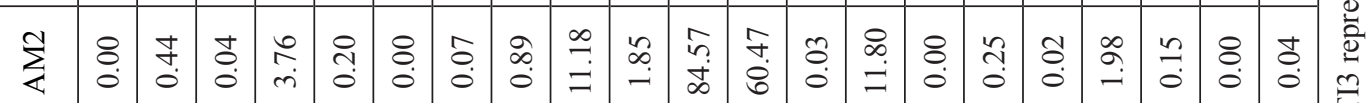

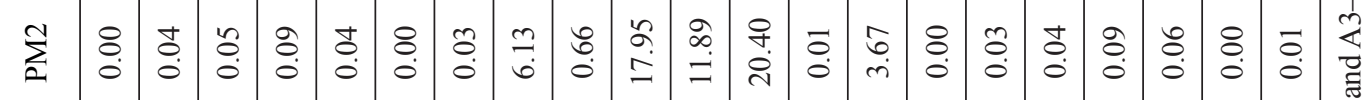

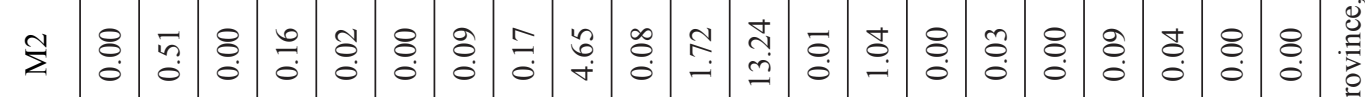

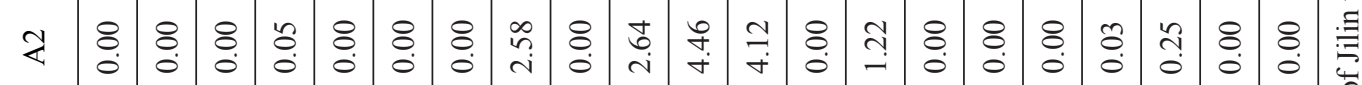

$\dot{\overrightarrow{\mathrm{B}}}$

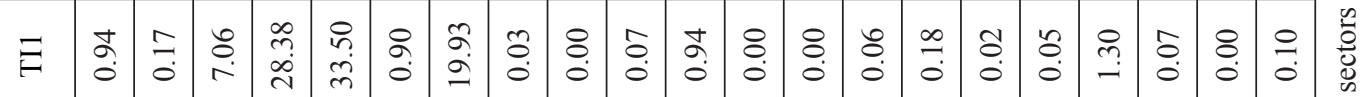

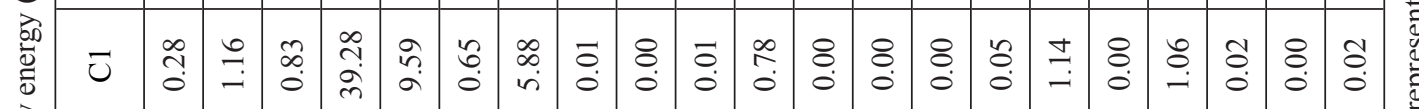

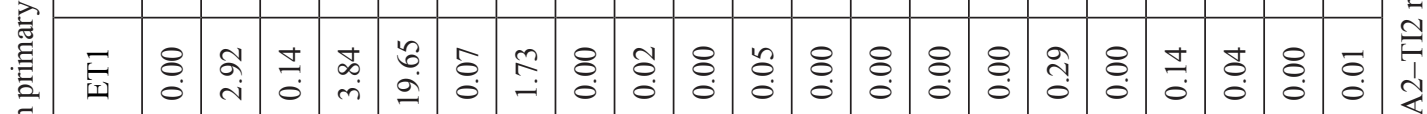

ヨ

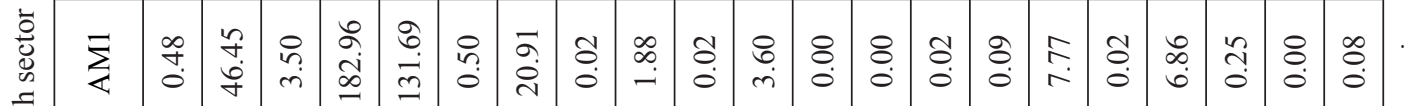

迎

峁

客

क्ष

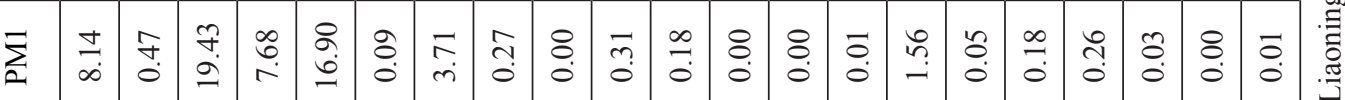

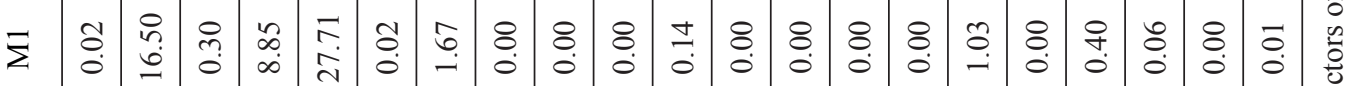

苛

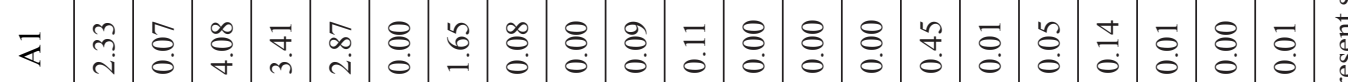

$\stackrel{g}{F}$

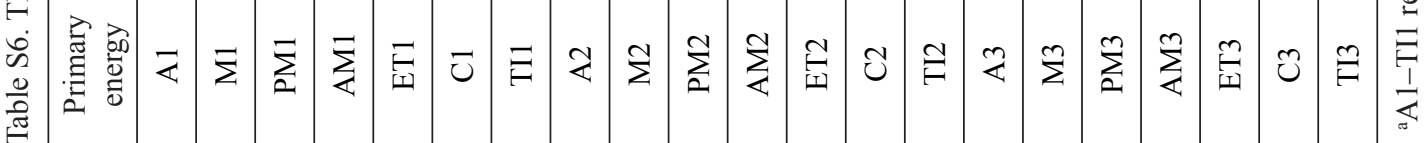




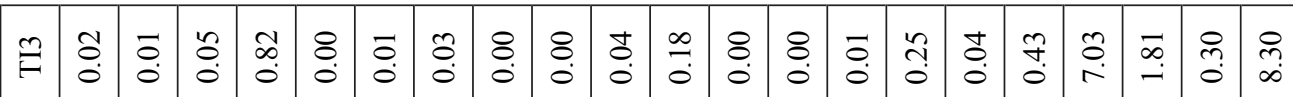

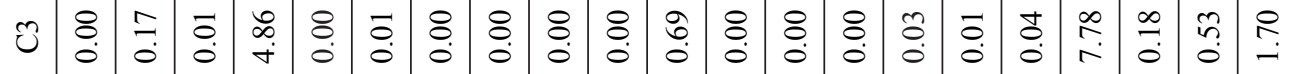
m

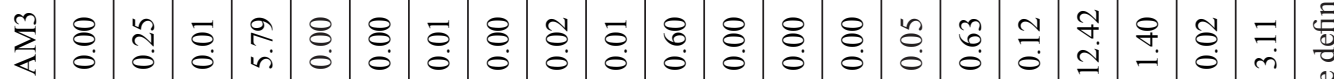

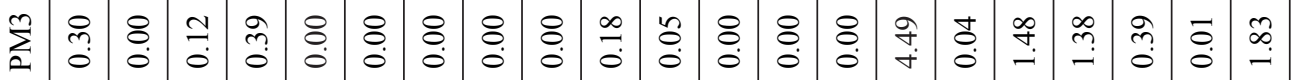

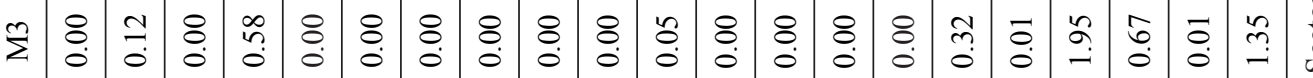

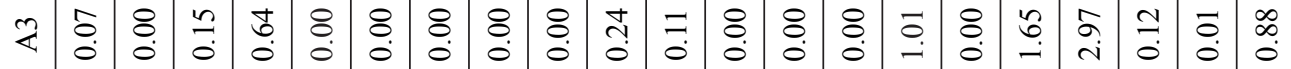

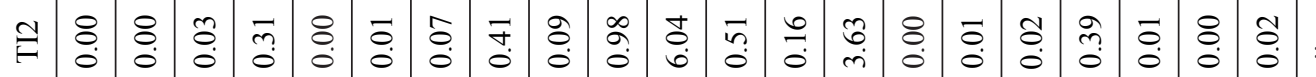
U T 事

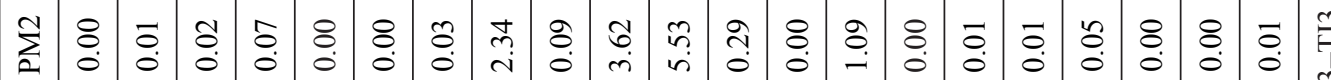

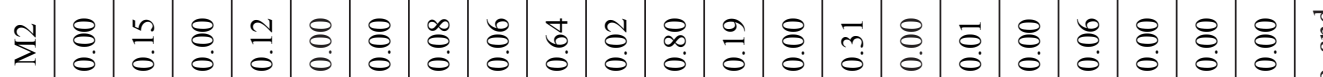

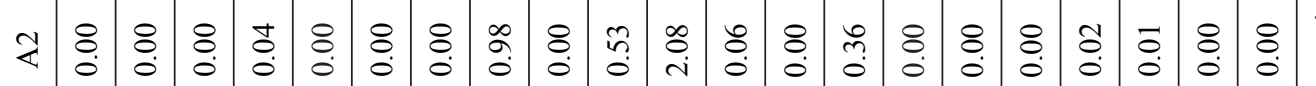

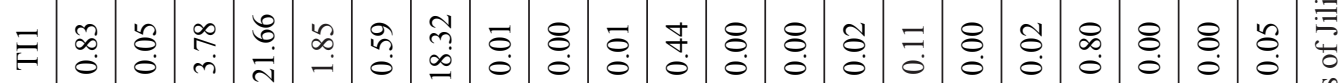

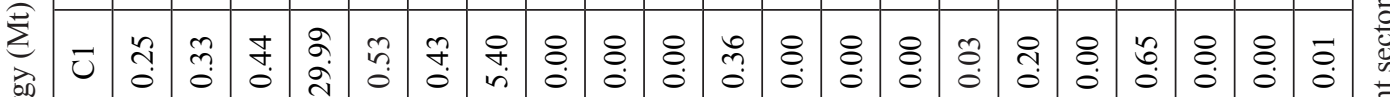
尊

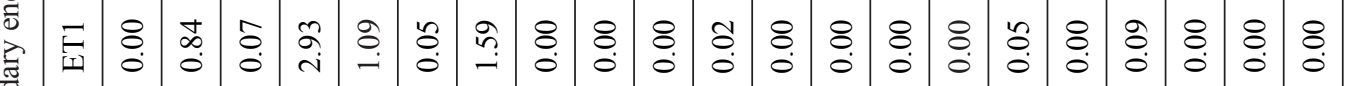

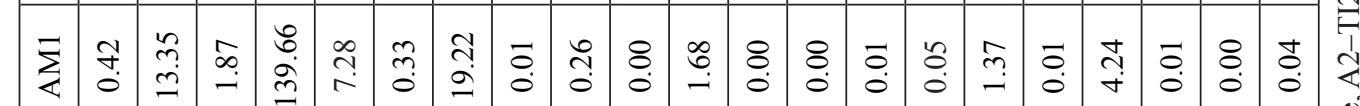

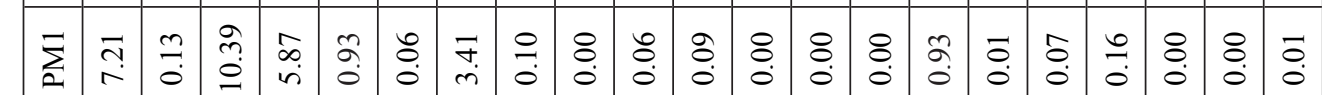

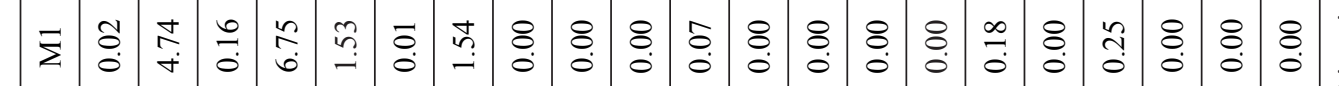

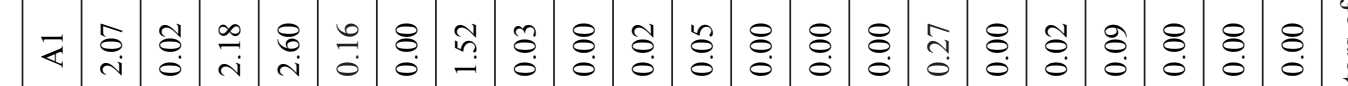




\begin{tabular}{|c|c|c|c|c|c|c|c|c|c|c|c|c|c|c|c|c|c|c|c|c|c|}
\hline & 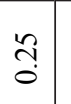 & $\stackrel{n}{I}$ & $\begin{array}{l}\mathscr{0} \\
? \\
0\end{array}$ & \begin{tabular}{l}
$n$ \\
\multirow{2}{*}{} \\
0 \\
0
\end{tabular} & $\underset{q}{g}$ & $\stackrel{\tilde{O}}{0}$ & $\cong$ & $\stackrel{\simeq}{\circ}$ & ô & 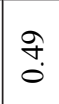 & 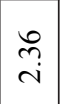 & 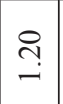 & $\stackrel{8}{0}$ & ָे & $\stackrel{\cong}{ت}$ & $\begin{array}{l}0 \\
\infty \\
i \\
i\end{array}$ & $\stackrel{\infty}{\underset{\longrightarrow}{\longrightarrow}}$ & $\begin{array}{l}\tilde{\alpha} \\
\check{\Omega}\end{array}$ & $\begin{array}{l}\hat{n} \\
\tilde{n}\end{array}$ & $\bar{n}$ & $\begin{array}{l}\hat{3} \\
\dot{0} \\
0\end{array}$ \\
\hline & ઼ָ & in & $\begin{array}{l}: \\
0 \\
0\end{array}$ & & & & & & $\bar{n}$ & $\vec{\jmath}$ & $\begin{array}{l}q \\
\dot{r}\end{array}$ & $\mid \begin{array}{c}\infty \\
\infty \\
-\end{array}$ & $\begin{array}{l}8 \\
0\end{array}$ & $\stackrel{q}{\stackrel{q}{0}}$ & సે & : & $\stackrel{+}{\tilde{c}}$ & $\bar{n}$ & $\stackrel{?}{\stackrel{?}{\circ}}$ & \begin{tabular}{l}
$\infty$ \\
\multirow{\sigma}{\sigma}{} \\
$\dot{\sigma}$
\end{tabular} & 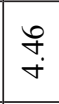 \\
\hline & ¿̊. & $f$ & $\begin{array}{l}\hat{0} \\
0\end{array}$ & & & $\overrightarrow{0}$ & & & $\stackrel{t}{0}$ & $\stackrel{o}{0}$ & خे & $\stackrel{7}{0}$ & $\stackrel{8}{0}$ & $\stackrel{\tilde{o}}{0}$ & $\begin{array}{l}8 \\
0\end{array}$ & $\begin{array}{l}? \\
\dot{0}\end{array}$ & $\begin{array}{l}\infty \\
0 \\
0\end{array}$ & $\begin{array}{l}\tilde{b} \\
i \\
i\end{array}$ & $\begin{array}{l}\vec{a} \\
\dot{\alpha} \\
\dot{d}\end{array}$ & $\stackrel{m}{0}$ & $\stackrel{\infty}{\stackrel{n}{\rightarrow}}$ \\
\hline & సે & $\underset{+}{\vec{F}}$ & $\begin{array}{l}\hat{\infty} \\
0 \\
0\end{array}$ & $\begin{array}{l}\vec{J} \\
\underset{\sim}{i}\end{array}$ & $\bar{\sigma}$ & $\hat{o}$ & & 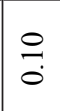 & $\stackrel{8}{0}$ & กี & $\begin{array}{l}\triangleright \\
\infty \\
\dot{r}\end{array}$ & $\begin{array}{l}\Delta \\
\vec{i} \\
i\end{array}$ & $\overrightarrow{0}$ & $\stackrel{f}{+}$ & 苂 & $\begin{array}{l}\forall \\
\dot{n}\end{array}$ & గో: & $\begin{array}{l}\text { ㅇ } \\
\text { İ } \\
\text { In }\end{array}$ & $\begin{array}{l}q \\
\stackrel{i}{i}\end{array}$ & $\stackrel{0}{0}$ & $\underset{\infty}{\stackrel{1}{0}}$ \\
\hline & $\stackrel{\vec{r}}{0}$ & $\stackrel{\leftrightarrow}{\circ}$ & 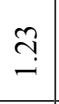 & $\widetilde{\infty}$ & & ठै. & & $\bar{F}$ & $\bar{a}$ & $\stackrel{\infty}{\infty}$ & $\begin{array}{l}n \\
b \\
i\end{array}$ & 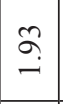 & $\begin{array}{l}8 \\
0 \\
0\end{array}$ & \begin{tabular}{l}
0 \\
\multirow{0}{0}{}
\end{tabular} & $\underset{f}{\forall}$ & $\stackrel{9}{=}$ & $\begin{array}{l}\stackrel{\text { I }}{+} \\
\text {. }\end{array}$ & $\vec{\jmath}$ & $\underset{\stackrel{F}{\Xi}}{\stackrel{F}{\Xi}}$ & $\begin{array}{l}\overline{0} \\
0\end{array}$ & 离 \\
\hline & $\stackrel{2}{\circ}$ & $\begin{array}{l}\infty \\
\infty \\
\infty\end{array}$ & $\Xi$ & $\overline{6}$ & & & & $\ddot{0}$ & $\stackrel{\infty}{\circ}$ & $\stackrel{\circ}{\circ}$ & 吕 & 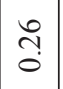 & $\stackrel{8}{0}$ & $\begin{array}{l}0 \\
\vdots \\
0\end{array}$ & $\stackrel{?}{0}$ & $\begin{array}{l}\hat{\infty} \\
\dot{f}\end{array}$ & $\stackrel{0}{\circ}$ & $\begin{array}{l}\text { \& } \\
\text { r. }\end{array}$ & $\begin{array}{l}n \\
0 \\
0\end{array}$ & $\stackrel{n}{0}$ & त̂ \\
\hline & f. & $\stackrel{\leftrightarrow}{o}$ & ? & $\nabla$ & $\approx$ & $\delta$ & & & ஸి & $\vec{m}$ & 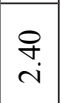 & $\mid \begin{array}{c}\infty \\
\stackrel{-}{-}\end{array}$ & $\begin{array}{l}8 \\
0\end{array}$ & $\stackrel{q}{\stackrel{q}{0}}$ & \begin{tabular}{|l}
8 \\
0 \\
0 \\
0
\end{tabular} & \begin{tabular}{|l|}
0 \\
$\infty$ \\
0 \\
0
\end{tabular} & $\begin{array}{l}\stackrel{\leftrightarrow}{i} \\
\text { in }\end{array}$ & $\begin{array}{l}\overrightarrow{0} \\
0\end{array}$ & $\begin{array}{l}\tilde{\sigma} \\
\infty \\
\infty\end{array}$ & $\begin{array}{l}0 \\
0 \\
0\end{array}$ & $\stackrel{亏}{F}$ \\
\hline & $\stackrel{8}{\circ}$ & $\stackrel{\sigma}{\sigma}$ & 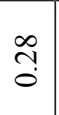 & 6 & ? & ô. & 7 & 8 & $\frac{9}{6}$ & $\stackrel{\overbrace{}}{\stackrel{f}{r}}$ & $\left|\begin{array}{c}\tilde{C} \\
i \\
\tilde{c}\end{array}\right|$ & 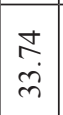 & $\begin{array}{l}\stackrel{0}{0} \\
\stackrel{0}{0}\end{array}$ & $\begin{array}{l}\circ \\
\circ \\
\circ\end{array}$ & 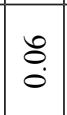 & $\stackrel{?}{\stackrel{f}{0}}$ & $\stackrel{0}{0}$ & $\stackrel{\vartheta}{\rightarrow}$ & $\stackrel{0}{=}$ & $\overrightarrow{0}$ & 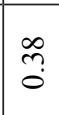 \\
\hline & $\stackrel{5}{\circ}$ & 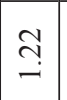 & กิ & in & & & & & $\stackrel{+}{\stackrel{+}{+}}$ & $\stackrel{\sim}{i}$ & $\begin{array}{l}\bar{a} \\
\vec{i}\end{array}$ & $\begin{array}{l}\stackrel{n}{\vec{v}} \\
\mid\end{array}$ & $\begin{array}{l}f \\
\dot{f} \\
\ddot{f}\end{array}$ & $\begin{array}{l}\underset{j}{N} \\
i\end{array}$ & $\begin{array}{l}\tilde{0} \\
\dot{0}\end{array}$ & $\stackrel{+}{3}$ & $\begin{array}{l} \pm \\
0 \\
0\end{array}$ & 点 & $\mid \begin{array}{l}n \\
\infty \\
0 \\
0\end{array}$ & $\stackrel{8}{0}$ & 足 \\
\hline & $\stackrel{\Xi}{\circ}$ & 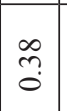 & $\stackrel{2}{\circ}$ & $\infty$ & $\stackrel{\text { If }}{0}$ & 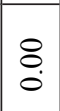 & & $\tilde{a}$ & त̂ & $\begin{array}{l}n \\
n \\
0 \\
0\end{array}$ & $\hat{\tilde{n}}$ & $\begin{array}{l}0 \\
\dot{0} \\
0 \\
-1\end{array}$ & $\begin{array}{l}\tilde{o} \\
\stackrel{0}{0}\end{array}$ & $\underset{-}{\stackrel{\theta}{a}}$ & $\overrightarrow{0}$ & $\stackrel{7}{0}$ & $\overrightarrow{0}$ & 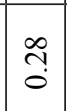 & $\begin{array}{l}0 \\
0 \\
0 \\
0\end{array}$ & 8 & oे \\
\hline & ஸิ & $\mid \begin{array}{l}8 \\
\dot{0} \\
\dot{1}\end{array}$ & $\stackrel{8}{\circ}$ & $\frac{8}{7}$ & $\begin{array}{l}\infty \\
\infty \\
\infty\end{array}$ & $\stackrel{5}{0}$ & $\underset{\dot{r}}{\stackrel{\Delta}{ }}$ & $\hat{\sigma}$ & $\begin{array}{l}\vec{\sim} \\
\underset{\lambda}{v}\end{array}$ & $\stackrel{\infty}{\stackrel{\infty}{\sim}}$ & 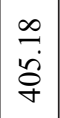 & $\begin{array}{l}N \\
\hat{\sigma} \\
\varrho\end{array}$ & ָे & $\begin{array}{l}\vec{\lambda} \\
\vec{\lambda}\end{array}$ & $\underset{7}{\dddot{0}}$ & $\vec{n}$ & $\begin{array}{l}0 \\
0 \\
0\end{array}$ & $\mid \begin{array}{l}0 \\
n \\
b\end{array}$ & $\begin{array}{l}\hat{r} \\
\dot{m}\end{array}$ & $\stackrel{d}{\sigma}$ & $\stackrel{\text { กิ }}{\text { S }}$ \\
\hline & $\stackrel{\infty}{0}$ & $\tilde{g}$ & $\tilde{a}$ & & s & & & & & $\begin{array}{l}\stackrel{\sim}{+} \\
\dot{d}\end{array}$ & $\underset{⿱ 亠 䒑}{\vec{\forall}}$ & & $\begin{array}{l}\circ \\
0 \\
0\end{array}$ & $\stackrel{\infty}{a}$ & $\begin{array}{l}8 \\
0\end{array}$ & \begin{tabular}{l}
0 \\
\hdashline \\
0
\end{tabular} & $\stackrel{0}{0}$ & $\stackrel{n}{n}$ & o̊ & $\begin{array}{l}8 \\
0\end{array}$ & $\hat{ָ}$ \\
\hline & $\stackrel{\text { ô }}{0}$ & $\stackrel{\vec{\sigma}}{\circ}$ & $\stackrel{8}{\circ}$ & z & & & & & & $\stackrel{0}{f}$ & $\stackrel{\underset{\sim}{\sim}}{+}$ & 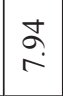 & $\begin{array}{l}\tilde{O} \\
\tilde{O}\end{array}$ & $\stackrel{\overbrace{}}{-}$ & $\ddot{\circ}$ & $\stackrel{2}{\circ}$ & $\stackrel{0}{\circ}$ & $\overbrace{0}^{0}$ & $\stackrel{\widetilde{\sigma}}{0}$ & $\stackrel{8}{\circ}$ & Oे \\
\hline & $\stackrel{0}{0}$ & त̃ & 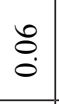 & ב & & & & & & $\stackrel{R}{i}$ & $\begin{array}{c}0 \\
\stackrel{1}{c} \\
\underline{C}\end{array}$ & $\begin{array}{l}n \\
\mathfrak{c} \\
0\end{array}$ & 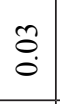 & $\begin{array}{l}\stackrel{0}{n} \\
i\end{array}$ & $\vec{\circ}$ & $\vec{Z}$ & $\ddot{\circ}$ & $\stackrel{0}{0}$ & @ి & $\stackrel{0}{0}$ & $\begin{array}{l}\infty \\
0 \\
0\end{array}$ \\
\hline & तु & 吕 & $\begin{array}{l}\infty \\
\pm \\
-\end{array}$ & $\stackrel{d}{0}$ & $\begin{array}{l}\text { in } \\
\text { ñ } \\
\text { in }\end{array}$ & & & & & in & $\stackrel{F}{i n}$ & $\mid \begin{array}{l}\infty \\
i n \\
\end{array}$ & $\overrightarrow{0}$ & $\begin{array}{l}\hat{0} \\
0\end{array}$ & $\stackrel{m}{\stackrel{m}{=}}$ & $\mid \begin{array}{c}0 \\
n \\
i\end{array}$ & $\tilde{n}$ & $\begin{array}{l}\Delta \\
\text { in }\end{array}$ & 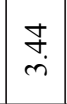 & ô. & 옴 \\
\hline & $\bar{\sigma}$ & 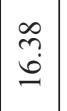 & $\begin{array}{l}\text { q } \\
\text { in }\end{array}$ & 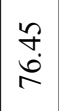 & $\mid \begin{array}{l}\infty \\
m \\
\stackrel{\sim}{\gamma}\end{array}$ & 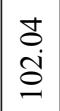 & & & & 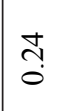 & $\begin{array}{l}\Delta \\
\dot{m}\end{array}$ & $\stackrel{8}{9}$ & $\ddot{0}$ & $\begin{array}{l} \pm \\
0 \\
0\end{array}$ & I̊ & 艿 & $\frac{0}{0}$ & $\begin{array}{l}\stackrel{\leftrightarrow}{q} \\
\dot{\gamma}\end{array}$ & $\vec{m}$ & $\begin{array}{l}\text { Oे } \\
0 \\
0\end{array}$ & $\stackrel{و}{=}$ \\
\hline & ֻొ & $\hat{\sigma}$ & $\stackrel{\circ}{0}$ & $\hat{n}$ & $\begin{array}{l}\bar{z} \\
z \\
\bar{z}\end{array}$ & 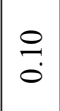 & $\lesssim$ & & & $\begin{array}{l}0 \\
0\end{array}$ & $\begin{array}{l}n \\
n \\
0\end{array}$ & 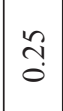 & 8 & $\stackrel{0}{\circ}$ & $\begin{array}{l}\infty \\
0 \\
0\end{array}$ & $\begin{array}{l}0 \\
0 \\
0\end{array}$ & $\stackrel{\leftrightarrow}{0}$ & $\begin{array}{l}+ \\
\stackrel{0}{0} \\
0\end{array}$ & $\vec{b}$ & \&. & సֶ. \\
\hline & $\underset{\infty}{\mathbb{\infty}}$ & $\begin{array}{c}\vec{m} \\
\dot{\alpha}\end{array}$ & $\begin{array}{l}\dot{d} \\
\dot{d} \\
\dot{d}\end{array}$ & ב气 & $\stackrel{\overbrace{}}{\overbrace{}}$ & 8 & $\begin{array}{l}8 \\
\vdots \\
0\end{array}$ & S. & $\begin{array}{l}n \\
\stackrel{n}{+}\end{array}$ & $\exists$ & $\stackrel{9}{a}$ & $\begin{array}{l}n \\
\\
0\end{array}$ & 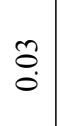 & $\underset{\sim}{\sim}$ & $\underset{\infty}{\infty}$ & $\begin{array}{l}q \\
q \\
m \\
m\end{array}$ & $\begin{array}{l} \pm \\
0 \\
0\end{array}$ & $\begin{array}{l}\vec{n} \\
\hat{n} \\
\end{array}$ & $\begin{array}{c}\hat{f} \\
\infty \\
-\end{array}$ & $\stackrel{\infty}{\circ}$ & $\tilde{n}$ \\
\hline & "ू & $\underset{\infty}{\stackrel{\infty}{\infty}}$ & $\stackrel{\infty}{2}$ & $\begin{array}{l}\tilde{N} \\
\tilde{n}\end{array}$ & $\begin{array}{c}\hat{j} \\
\infty \\
d\end{array}$ & s & $\begin{array}{l}8 \\
9\end{array}$ & t) & $\hat{n}$ & $\stackrel{2}{3}$ & $\begin{array}{l}\dot{b} \\
\infty \\
\dot{n}\end{array}$ & $\begin{array}{l}\stackrel{\sim}{\mathrm{C}} \\
\mathrm{i}\end{array}$ & $\overrightarrow{0}$ & $\begin{array}{l}\stackrel{0}{ } \\
:\end{array}$ & $\begin{array}{l}0 \\
\stackrel{n}{n} \\
\tilde{n}\end{array}$ & $\stackrel{\tilde{m}}{\longrightarrow}$ & $\vec{n}$ & $\underset{+}{\stackrel{\sigma}{+}}$ & $\stackrel{\sim}{\sim}$ & ô. & $\underset{\sigma}{\sigma}$ \\
\hline & :े. & $\frac{ \pm}{\stackrel{0}{\circ}}$ & $\begin{array}{l}n \\
c \\
i\end{array}$ & $\begin{array}{l}n \\
n \\
a \\
\hat{n}\end{array}$ & $\begin{array}{l}\text { ले } \\
\text { ते }\end{array}$ & $\frac{7}{c}$ & $\sqrt{5}$ & & $\grave{ָ}$ & $\stackrel{\infty}{\circ}$ & $\stackrel{\widehat{N}}{-}$ & $\hat{n}$ & 8 & $\stackrel{m}{0}$ & $\stackrel{n}{0}$ & 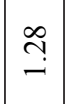 & $\stackrel{0}{0}$ & $\stackrel{\sim}{i}$ & $\stackrel{\Re}{=}$ & $\ddot{\circ}$ & $\begin{array}{l}8 \\
0 \\
0\end{array}$ \\
\hline & $\begin{array}{l}\text { ஃे } \\
\text { ले }\end{array}$ & $\vec{i}$ & 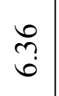 & $\begin{array}{l}0 \\
\stackrel{0}{6}\end{array}$ & $\begin{array}{l}\infty \\
0 \\
0\end{array}$ & d & $\stackrel{\leftrightarrow}{\dot{r}}$ & $\stackrel{\circ}{\circ}$ & $\stackrel{\infty}{\stackrel{0}{0}}$ & $\stackrel{n}{0}$ & $\stackrel{\infty}{=}$ & $\begin{array}{l}\hat{6} \\
0\end{array}$ & $\begin{array}{l}8 \\
0\end{array}$ & $\stackrel{7}{0}$ & $\mid \begin{array}{c}\vec{\infty} \\
0 \\
0\end{array}$ & f̊ & $\stackrel{q}{0}$ & 导 & $\vec{a}$ & $\overrightarrow{0}$ & 号 \\
\hline & & $\Sigma$ & $\gtrsim$ & $\bar{z}$ & $\vec{F}$ & $\bar{U}$ & $\Xi$ & Z & $\tilde{\Sigma}$ & $\sum_{i}^{\mathfrak{N}}$ & $\sum_{<}^{\tilde{Z}}$ & $\underline{\Gamma}$ & & $\stackrel{?}{\vec{E}}$ & & $\sum^{m}$ & $\sum_{\Sigma}^{\infty}$ & $\sum_{<}^{\infty}$ & 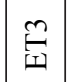 & $\tilde{\delta}$ & 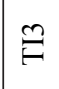 \\
\hline
\end{tabular}




\begin{tabular}{|c|c|c|c|c|c|c|c|c|c|c|c|c|c|c|c|c|c|c|c|c|c|c|}
\hline$\stackrel{\mathscr{E}}{\boxminus}$ & $\stackrel{9}{0}$ & 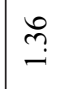 & חై & $\hat{n}$ & 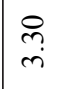 & Oे & in & & $\begin{array}{l}2 \\
\stackrel{0}{0} \\
\dot{0}\end{array}$ & 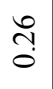 & ఫ. & $\stackrel{\vec{\sigma}}{-}$ & $\stackrel{9}{\leftrightarrows}$ & $\stackrel{8}{0}$ & $\stackrel{\overbrace{}}{0}$ & & $\stackrel{\text { f }}{i}$ & $\hat{\sigma}$ & $\begin{array}{l}\tilde{\alpha} \\
\dot{\sigma}\end{array}$ & 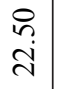 & तิ & $\begin{array}{l}\hat{\sigma} \\
\tilde{\sigma}\end{array}$ \\
\hline ש & $=$ & $\stackrel{i}{i}$ & $\stackrel{\text { fี }}{5}$ & ț & $\stackrel{2}{\stackrel{2}{r}}$ & ${ }_{0}^{t}$ & $\stackrel{\text { I }}{~}$ & & \begin{tabular}{l}
8 \\
\hdashline \\
0
\end{tabular} & 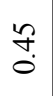 & $\stackrel{\infty}{0}$ & $\tilde{\overbrace{}}$ & $\stackrel{\mathscr{S}}{-\infty}$ & 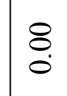 & $\tilde{o}$ & $\stackrel{\infty}{0}$ & $\underset{\Xi}{\stackrel{F}{*}}$ & $\begin{array}{l}n \\
\tilde{o} \\
0\end{array}$ & $\begin{array}{l}\infty \\
\infty \\
\infty \\
\text { in }\end{array}$ & $\stackrel{2}{\alpha}$ & $\begin{array}{l}\stackrel{2}{2} \\
\stackrel{\lambda}{2}\end{array}$ & $\underset{\dot{m}}{\Delta}$ \\
\hline$\stackrel{2}{I}$ & $\stackrel{\overrightarrow{0}}{\circ}$ & के & $\stackrel{n}{0}$ & $\vec{\beth}$ & $\stackrel{t}{\stackrel{0}{0}}$ & $\stackrel{8}{0}$ & $\stackrel{7}{0}$ & & $\begin{array}{l}8 \\
0 \\
0\end{array}$ & $\begin{array}{l}\tilde{o} \\
0\end{array}$ & ¿े. & กิ & $\overline{0}$ & $\stackrel{8}{0}$ & Oे & 苟 & 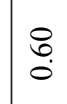 & $\begin{array}{l}8 \\
0 \\
0\end{array}$ & $\stackrel{\widetilde{\sigma}}{-}$ & 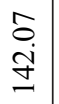 & 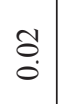 & $\stackrel{\infty}{\stackrel{\circ}{-}}$ \\
\hline$\sum_{4}$ & $\stackrel{0}{0}$ & 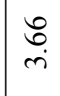 & ñ & $\overrightarrow{\stackrel{i}{I}}$ & 字 & $\stackrel{t}{0}$ & 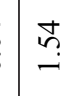 & & $\begin{array}{l}\infty \\
0 \\
0 \\
0\end{array}$ & है & ֻั & $\stackrel{\text { ڤn }}{\text { r. }}$ & $\underset{\mathrm{i}}{\vec{i}}$ & $\stackrel{8}{\circ}$ & ?. & ñ & $\hat{\widehat{i}}$ & $\stackrel{f}{f}$ & \begin{tabular}{|c|}
$\vec{\infty}$ \\
$\stackrel{0}{0}$ \\
\end{tabular} & $\begin{array}{l}\stackrel{q}{q} \\
\stackrel{9}{q}\end{array}$ & $\stackrel{\circ}{\circ}$ & $\begin{array}{l}\text { in } \\
\text { in }\end{array}$ \\
\hline$\sum_{\Omega}^{n}$ & $\stackrel{\infty}{\stackrel{\infty}{0}}$ & $\begin{array}{l}\infty \\
\stackrel{\infty}{0}\end{array}$ & $\begin{array}{l}0 \\
\stackrel{\infty}{0} \\
0\end{array}$ & $\begin{array}{c}\infty \\
\infty \\
\sim\end{array}$ & 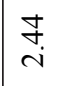 & $\ddot{\Xi}$ & n? & & ते & $\stackrel{\widehat{o}}{0}$ & $\stackrel{\overbrace{}}{?}$ & $\stackrel{\infty}{-}$ & $\stackrel{9}{-}$ & $\stackrel{8}{\circ}$ & $\stackrel{n}{n}$ & $\stackrel{\infty}{i}$ & \& & & गे & $\begin{array}{l}\infty \\
\stackrel{\infty}{\infty} \\
\stackrel{0}{\bullet}\end{array}$ & $\stackrel{0}{0}$ & $\stackrel{\vec{f}}{+}$ \\
\hline$\sum$ & ชి & 常 & $\stackrel{\partial}{\circ}$ & $\underset{i}{\stackrel{t}{i}}$ & $\stackrel{\infty}{\stackrel{\infty}{\rightarrow}}$ & $\ddot{0}$ & 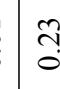 & & $\overrightarrow{0}$ & $\stackrel{1}{0}$ & $\stackrel{n}{0}$ & 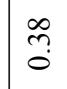 & 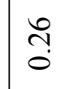 & $\stackrel{8}{0}$ & 旾 & 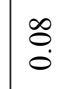 & $\begin{array}{l}n \\
\infty \\
\infty \\
m\end{array}$ & $\stackrel{\sim}{0}$ & $\underset{\vec{i}}{\vec{J}}$ & $\begin{array}{l}\infty \\
i \\
i\end{array}$ & $\stackrel{t}{0}$ & I \\
\hline 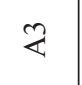 & ๙ึ? & $\stackrel{t}{\stackrel{0}{0}}$ & $\bar{n}$ & 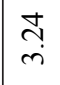 & $\stackrel{m}{i}$ & o. & 导 & & $\begin{array}{c}\bar{y} \\
\tilde{0}\end{array}$ & 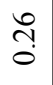 & $\stackrel{g}{\mathrm{~g}}$ & $\underset{-}{\mathbb{Z}}$ & $\stackrel{\infty}{\stackrel{\infty}{-}}$ & $\stackrel{8}{0}$ & $\stackrel{m}{0}$ & $\begin{array}{l}\stackrel{n}{n} \\
\end{array}$ & $\stackrel{\overbrace{}}{0}$ & $\stackrel{\beta}{-}$ & $\begin{array}{l}\partial \\
\dot{+}\end{array}$ & $\stackrel{\bullet}{\stackrel{0}{\circ}}$ & $\stackrel{t}{0}$ & $\begin{array}{l}+ \\
\stackrel{\infty}{+} \\
i\end{array}$ \\
\hline$\stackrel{?}{F}$ & $\stackrel{n}{0}$ & $\stackrel{\hat{\sigma}}{\circ}$ & $\stackrel{\infty}{\circ}$ & $\underset{i}{\mathbb{i}}$ & 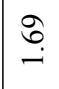 & $\stackrel{\square}{\circ}$ & $\stackrel{\tilde{m}}{0}$ & & 趈 & $\begin{array}{l}\text { 守 } \\
\text { in }\end{array}$ & ָี & 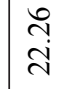 & 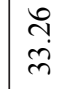 & $\stackrel{7}{0}$ & $\underset{+}{\stackrel{+}{+}}$ & 志 & ח̊ & $\stackrel{n}{0}$ & $\exists$ & $\stackrel{\varrho}{\leftrightarrows}$ & $\stackrel{8}{\circ}$ & $\begin{array}{l}\text { ז̊ } \\
\text { ஸे }\end{array}$ \\
\hline ป & $\stackrel{\overbrace{}}{\circ}$ & $\stackrel{t}{0}$ & $\stackrel{n}{0}$ & $\stackrel{0}{\stackrel{m}{m}}$ & $\stackrel{\infty}{i}$ & $\stackrel{0}{\circ}$ & 导 & & $\begin{array}{c}+ \\
\dot{0}\end{array}$ & बे. & $\stackrel{0}{\stackrel{2}{+}}$ & $\begin{array}{l}\infty \\
\infty \\
0 \\
0\end{array}$ & \begin{tabular}{|l}
$\dot{d}$ \\
$\dot{\vec{N}}$
\end{tabular} & $\begin{array}{l}\hat{b} \\
\text { i } \\
\text { r }\end{array}$ & $\underset{+}{\stackrel{+}{+}}$ & ô. & సิ & $\hat{o}$ & $\begin{array}{l}0 \\
0 \\
0\end{array}$ & $\begin{array}{l}\vec{\infty} \\
0\end{array}$ & $\stackrel{8}{0}$ & $\stackrel{2}{0}$ \\
\hline$\stackrel{F}{I}$ & $\stackrel{\square}{\circ}$ & i্ & $\stackrel{3}{0}$ & $\stackrel{0}{1}$ & $\stackrel{f}{0}$ & $\stackrel{8}{\circ}$ & $\stackrel{\circ}{0}$ & & $\frac{5}{0}$ & $\stackrel{\infty}{\rightarrow}$ & तิ & $\underset{\mathrm{i}}{\mathrm{i}}$ & $\begin{array}{l}0 \\
\tilde{n} \\
\tilde{\sigma} \\
0\end{array}$ & $\ddot{0}$ & $\begin{array}{l}\mathbf{1} \\
\stackrel{\infty}{0} \\
0\end{array}$ & $\stackrel{8}{0}$ & $\stackrel{0}{0}$ & $\overrightarrow{0}$ & $\stackrel{7}{0}$ & సิ & $\stackrel{8}{\circ}$ & $\stackrel{0}{\circ}$ \\
\hline$\sum$ & $\stackrel{ \pm}{0}$ & $\stackrel{\tilde{m}}{\dot{m}}$ & ڤิ & $\stackrel{\text { I }}{\mathrm{I}}$ & $\underset{\infty}{ \pm}$ & $\stackrel{t}{0}$ & $\stackrel{\infty}{n}$ & & $\begin{array}{c}\infty \\
\dot{\infty} \\
i\end{array}$ & $\begin{array}{l}\stackrel{q}{\dot{d}} \\
\stackrel{\sim}{\mathrm{d}}\end{array}$ & ఫुे & 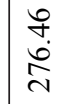 & $\mid \begin{array}{l}\tilde{N} \\
\tilde{S} \\
\underline{O}\end{array}$ & $\vec{\jmath}$ & $\begin{array}{l}\stackrel{2}{2} \\
\stackrel{2}{\beth}\end{array}$ & $\stackrel{\infty}{\circ}$ & ते & $\overrightarrow{0}$ & $\begin{array}{l}n \\
\dot{f} \\
\dot{f}\end{array}$ & $\begin{array}{l}\dot{l} \\
\stackrel{1}{r}\end{array}$ & $\stackrel{0}{\circ}$ & $\begin{array}{l}\widetilde{D} \\
\infty \\
0\end{array}$ \\
\hline$\sum_{\Omega}^{\mathfrak{V}}$ & 苛 & $\stackrel{\mathbb{0}}{0}$ & $\stackrel{7}{0}$ & $\hat{\tilde{i}}$ & $\stackrel{f}{-}$ & $\stackrel{\Xi}{\circ}$ & $\bar{m}$ & & $\begin{array}{c}n \\
\stackrel{n}{*} \\
\dot{f}\end{array}$ & ñ & $\begin{array}{c}\underset{m}{\infty} \\
\stackrel{\infty}{\infty}\end{array}$ & 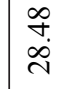 & 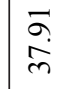 & $\stackrel{0}{0}$ & $\stackrel{\infty}{\stackrel{\infty}{r}}$ & Oे. & $\overline{\tilde{o}}$ & ô & å & ふ઼ & $\stackrel{8}{0}$ & $\stackrel{\infty}{0}$ \\
\hline$\tilde{\Sigma}$ & $\ddot{\circ}$ & $\stackrel{f}{\circ}$ & $\stackrel{8}{\circ}$ & $\begin{array}{l}0 \\
\infty \\
0\end{array}$ & $\begin{array}{l}0 \\
0 \\
0\end{array}$ & & & & $\overrightarrow{\widetilde{\sigma}}$ & & \begin{tabular}{c}
$\infty$ \\
\multirow{2}{0}{} \\
0
\end{tabular} & $\underset{\sim}{\tilde{n}}$ & $\stackrel{\infty}{\stackrel{\infty}{\sim}}$ & ô. & 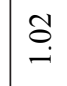 & $\overrightarrow{0}$ & $\stackrel{\circ}{0}$ & $\overrightarrow{0}$ & $\vec{\jmath}$ & ָ̃ & $\stackrel{8}{\circ}$ & $\stackrel{\leftrightarrow}{0}$ \\
\hline$\frac{\pi}{4}$ & $\stackrel{\square}{\circ}$ & $\overrightarrow{\widetilde{\sigma}}$ & $\stackrel{0}{0}_{0}^{t}$ & $\stackrel{N}{0}$ & $\stackrel{f}{\stackrel{f}{0}}$ & $\stackrel{8}{\circ}$ & 8 & & 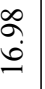 & $\overrightarrow{\breve{n}}$ & ત્ & $\underset{\infty}{\grave{\infty}}$ & $\vec{\exists}$ & $\stackrel{\sigma}{0}$ & $\widehat{a}$ & $\overrightarrow{0}$ & oे & $\begin{array}{l}\overrightarrow{0} \\
0\end{array}$ & స़े & 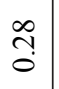 & $\stackrel{8}{\circ}$ & $\stackrel{n}{0}$ \\
\hline$\exists$ & 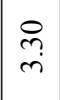 & 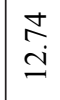 & $\begin{array}{l}\stackrel{d}{b} \\
\stackrel{0}{\circ}\end{array}$ & $\begin{array}{l}\bar{n} \\
\stackrel{n}{n}\end{array}$ & 芯 & fै & & & $\begin{array}{l}\stackrel{\Delta}{\Delta} \\
0 \\
0\end{array}$ & $\begin{array}{l} \pm \\
\infty \\
0 \\
0\end{array}$ & gै. & $\hat{n}$ & $\begin{array}{l}\stackrel{+}{n} \\
\text { in }\end{array}$ & $\ddot{\sigma}$ & q) & 犃 & $\stackrel{m}{\vec{i}}$ & \begin{tabular}{l}
$\infty$ \\
\hdashline \\
0
\end{tabular} & $\begin{array}{c}\hat{\sigma} \\
\dot{r}\end{array}$ & $\begin{array}{l}\stackrel{\infty}{N} \\
\sim \\
\sim\end{array}$ & $\ddot{\circ}$ & $\stackrel{n}{o}$ \\
\hline$\vec{U}$ & $\stackrel{\overrightarrow{-}}{\circ}$ & 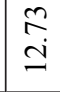 & $\tilde{n}$ & 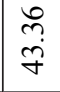 & $\begin{array}{l}\exists \\
\vec{F}\end{array}$ & & & & $\frac{0}{0}$ & $\stackrel{n}{\mathfrak{0}}$ & ָั & $\underset{i}{a}$ & $\stackrel{\infty}{\infty}$ & $\stackrel{8}{\circ}$ & m. & ઼ָ & $\frac{n}{i}$ & $\frac{ \pm}{0}$ & $\underset{r}{\mathscr{r}}$ & $\stackrel{n}{m}$ & $\bar{\sigma}_{0}$ & $\begin{array}{l}\overrightarrow{0} \\
\dot{0}\end{array}$ \\
\hline I & $\frac{2}{0}$ & $\begin{array}{l}\infty \\
\infty \\
i\end{array}$ & $\stackrel{?}{\circ}$ & 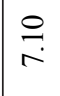 & $\begin{array}{l}\text { ర్ } \\
\text { तें }\end{array}$ & ๑ & 5 & & 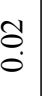 & $\begin{array}{l}\stackrel{0}{0} \\
0\end{array}$ & $\stackrel{\leftrightarrow}{\circ}$ & $\hat{n}$ & ત̂̀ & $\stackrel{8}{0}$ & $\stackrel{n}{\circ}$ & 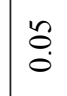 & ڤે. & $\begin{array}{l}1 \\
\delta \\
0\end{array}$ & ñ & $\stackrel{\infty}{n}$ & $\stackrel{0}{\circ}$ & $\stackrel{n}{0}$ \\
\hline$\sum$ & 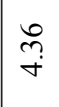 & $\begin{array}{l}\tilde{丶} \\
\stackrel{+}{T}\end{array}$ & $\begin{array}{l}8 \\
\stackrel{0}{0}\end{array}$ & \begin{tabular}{|l}
$\bar{\sigma}$ \\
Jud
\end{tabular} & $\begin{array}{l}\mathbb{J} \\
\text { i } \\
\text { Z }\end{array}$ & 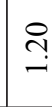 & $\mid \begin{array}{l}n \\
\infty \\
\infty\end{array}$ & & fo & $\begin{array}{l}\stackrel{8}{+} \\
+\end{array}$ & $\hat{\delta}$ & $\begin{array}{l}\dot{0} \\
\dot{m}\end{array}$ & $\stackrel{ }{\circ}$ & $\stackrel{\text { Oे }}{\circ}$ & 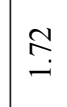 & $\stackrel{ \pm}{\leftrightarrows}$ & $\stackrel{f}{\Xi}$ & $\begin{array}{l}\vec{b} \\
\dot{0}\end{array}$ & $\begin{array}{l}0 \\
2 \\
i \\
2\end{array}$ & 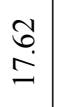 & $\stackrel{\leftrightarrow}{0}$ & $\underset{+}{\stackrel{f}{+}}$ \\
\hline$\sum$ & $\stackrel{?}{r}$ & $\frac{\infty}{\delta}$ & $\stackrel{\infty}{\stackrel{\infty}{\Re}}$ & $\frac{\infty}{\stackrel{0}{\infty}}$ & శే & 1 & & & $\hat{n}$ & & $\stackrel{\circ}{\rightleftarrows}$ & $\begin{array}{l}\underset{S}{S} \\
\text { i }\end{array}$ & $\stackrel{\vec{i}}{i}$ & $\stackrel{8}{0}$ & $\stackrel{?}{\circ}$ & ro & $\stackrel{\bullet}{\rightleftarrows}$ & $\stackrel{\partial}{-}$ & $\begin{array}{c}\infty \\
\stackrel{0}{r} \\
\dot{r}\end{array}$ & $\hat{\mathrm{i}}$ & $\stackrel{\square}{\circ}$ & $\stackrel{\circ}{\rightleftarrows}$ \\
\hline $\bar{z}$ & ?̊. & $\stackrel{\substack{\infty \\
+\infty}}{+\infty}$ & $\stackrel{ \pm}{\rightarrow}$ & $\begin{array}{l}\stackrel{0}{0} \\
\omega\end{array}$ & $\begin{array}{l}8 \\
\stackrel{+}{+}\end{array}$ & $\stackrel{0}{\circ}$ & 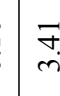 & & $\begin{array}{l}\tilde{o}_{0} \\
\stackrel{0}{0}\end{array}$ & 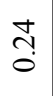 & o. & $\begin{array}{c}\infty \\
0 \\
0\end{array}$ & $\begin{array}{l}0 \\
\stackrel{n}{0} \\
0\end{array}$ & $\stackrel{8}{0}$ & $\stackrel{\circ}{0}$ & $\stackrel{\circ}{\circ}$ & $\stackrel{g}{g}$ & $\mid \begin{array}{l}n \\
0 \\
0\end{array}$ & $\vec{n}$ & $\stackrel{n}{6}$ & $\stackrel{8}{\circ}$ & $\stackrel{F}{\circ}$ \\
\hline$z$ & 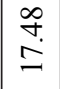 & $\stackrel{\circ}{\stackrel{i}{i}}$ & $\stackrel{n}{\rightarrow}$ & $\stackrel{7}{a}$ & 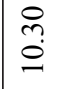 & o. & $\hat{n}$ & & $\stackrel{ \pm}{ \pm}$ & $\begin{array}{l}0 \\
0 \\
0\end{array}$ & ते & $\begin{array}{l}\bar{\infty} \\
\stackrel{0}{0}\end{array}$ & $\begin{array}{l}: \\
:\end{array}$ & $\stackrel{8}{8}$ & $\stackrel{2}{0}$ & $\vec{n}$ & ?ִ & ते & $\bar{\sigma}$ & $\begin{array}{l}\hat{\infty} \\
0 \\
0\end{array}$ & $\stackrel{8}{\circ}$ & $\bar{m}$ \\
\hline 5 & 飞 & $\bar{\Sigma}$ & $\sum_{\Omega}$ & $\sum_{4}$ & $\vec{F}$ & $\bar{U}$ & $E$ & & $\frac{1}{4}$ & $\tilde{\Sigma}$ & 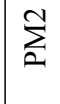 & $\sum^{\mathfrak{Z}}$ & $\stackrel{\vec{F}}{\vec{I}}$ & U & $\stackrel{?}{*}$ & $\stackrel{2}{\gtrless}$ & $\stackrel{m}{\Sigma}$ & $\sum_{i}^{n}$ & $\sum_{<}^{n}$ & $\stackrel{n}{\mu}$ & $\tilde{3}$ & $\hat{\theta}$ \\
\hline
\end{tabular}




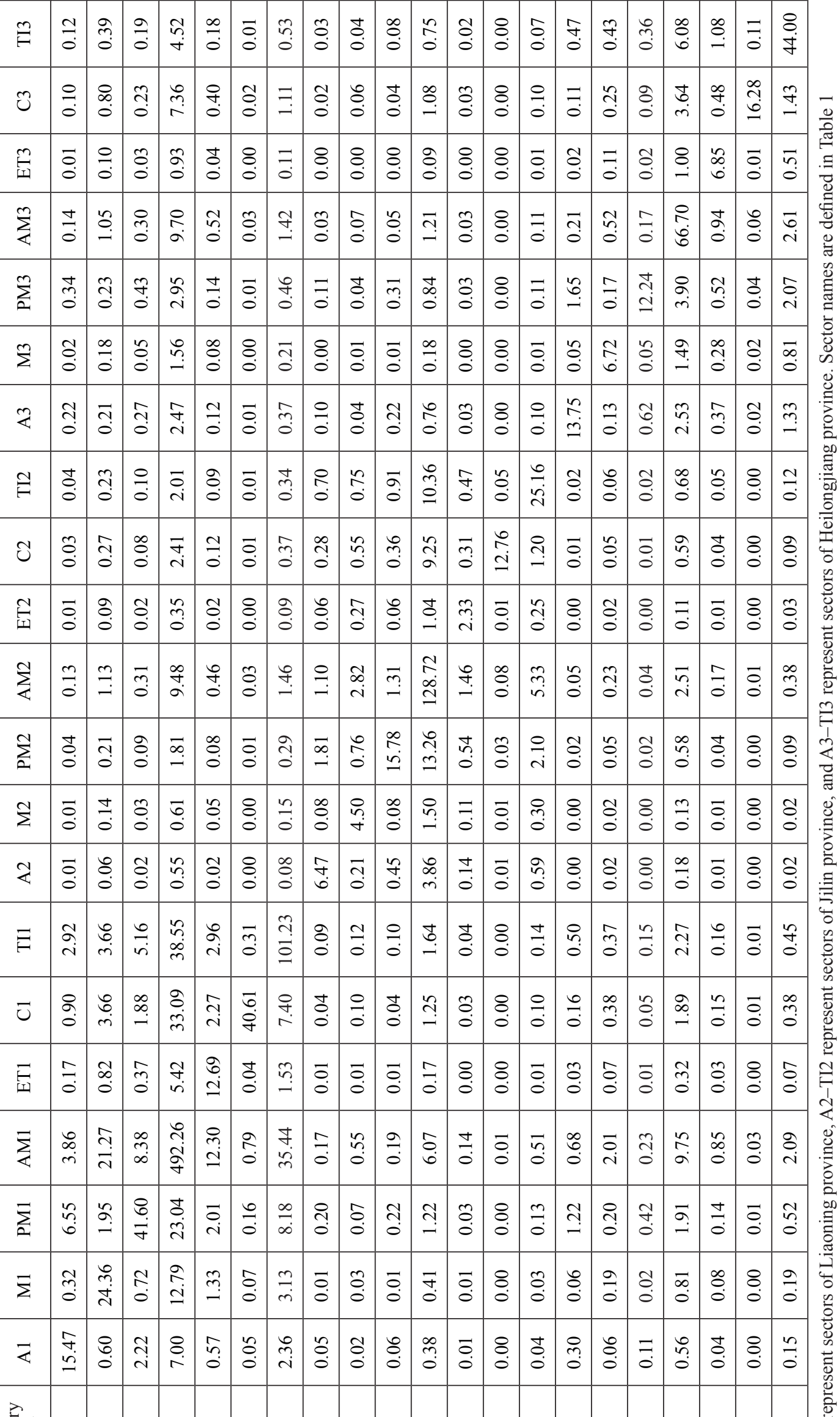

$\stackrel{g}{E}$

ڤ

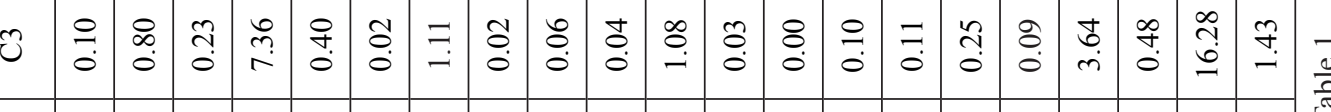

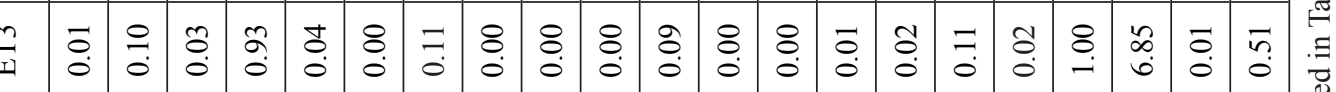

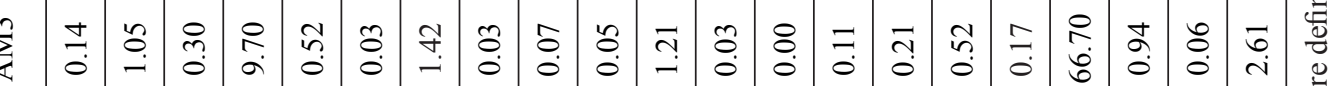

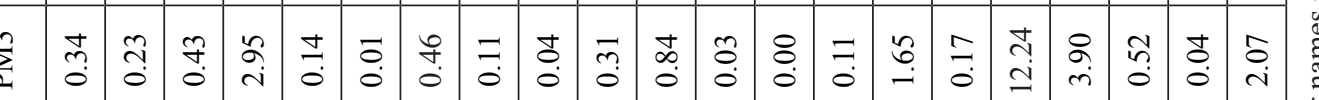

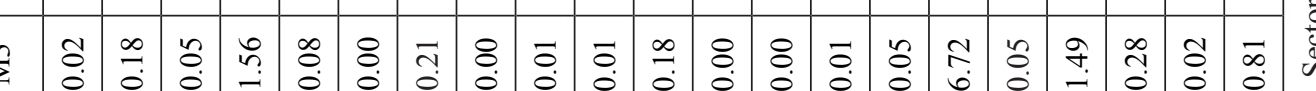

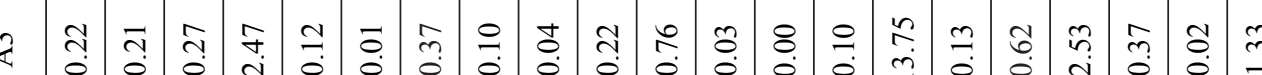
ป T ¿

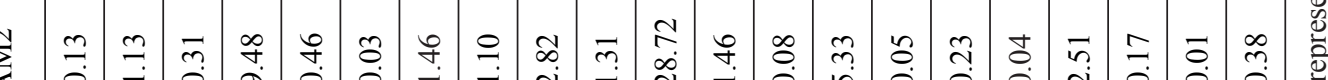

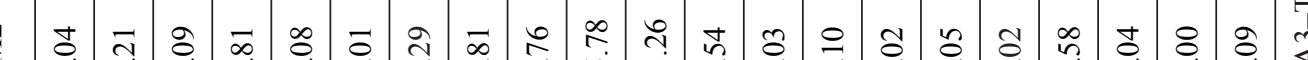

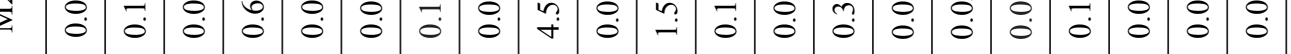

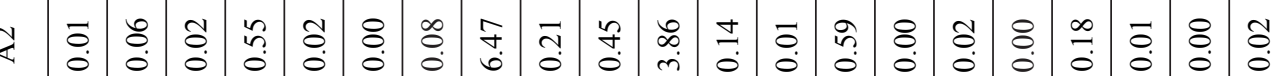


The Values for Direct and Indirect Carbon Emissions of Each Sector

Table S11. The Direct emissions and Indirect emissions of different sectors in all energy, primary energy and secondary energy.

\begin{tabular}{|c|c|c|c|c|c|c|}
\hline \multirow[b]{2}{*}{ Sector } & \multicolumn{3}{|c|}{ Direct emissions (Mt) } & \multicolumn{3}{|c|}{ Indirect emissions (Mt) } \\
\hline & All energy & Primary energy & Secondary energy & All energy & Primary energy & Secondary energy \\
\hline A1 & 5.23 & 0.350 & 4.88 & 24.4 & 15.4 & 9.02 \\
\hline M1 & 25.5 & 19.0 & 6.49 & 72.0 & 56.7 & 15.3 \\
\hline PM1 & 4.45 & 1.41 & 3.04 & 88.7 & 59.3 & 29.43 \\
\hline AM1 & 168 & 26.6 & 141 & 597 & 407 & 190 \\
\hline ET1 & 197 & 191 & 5.42 & 35.7 & 28.9 & 6.74 \\
\hline $\mathrm{C} 1$ & 2.19 & 0.400 & 1.79 & 99.4 & 60.8 & 38.7 \\
\hline TI1 & 43.8 & 3.227 & 1.93 & 142 & 93.8 & 48.6 \\
\hline $\mathrm{A} 2$ & 2.38 & 0.444 & 1.78 & 19.4 & 15.4 & 4.09 \\
\hline M2 & 10.5 & 8.74 & 0.51 & 24.3 & 21.9 & 2.44 \\
\hline PM2 & 7.26 & 6.75 & 38.0 & 74.4 & 61.1 & 13.2 \\
\hline AM2 & 50.3 & 12.2 & 0.50 & 228 & 178 & 50.4 \\
\hline ET2 & 133 & 132 & 1.07 & 25.3 & 23.6 & 1.72 \\
\hline $\mathrm{C} 2$ & 1.38 & 0.309 & 10.6 & 44.0 & 32.3 & 11.7 \\
\hline TI2 & 19.3 & 8.73 & 1.93 & 82.3 & 69.6 & 12.7 \\
\hline A3 & 8.12 & 3.37 & 4.75 & 25.7 & 17.9 & 7.86 \\
\hline M3 & 15.7 & 14.2 & 1.49 & 28.2 & 23.1 & 5.08 \\
\hline PM3 & 1.08 & 0.746 & 0.33 & 38.7 & 28.0 & 10.7 \\
\hline AM3 & 64.6 & 28.4 & 36.3 & 94.2 & 69.7 & 24.5 \\
\hline ET3 & 128 & 124 & 3.57 & 17.1 & 14.0 & 3.08 \\
\hline $\mathrm{C} 3$ & 0.211 & 0.000 & 0.21 & 45.6 & 29.6 & 16.0 \\
\hline $\mathrm{TI} 3$ & 36.0 & 15.0 & 21.0 & 90.1 & 70.8 & 19.3 \\
\hline
\end{tabular}

${ }^{\mathrm{a}} \mathrm{A} 1-\mathrm{TI} 1$ represent sectors of Liaoning province, A2-TI2 represent sectors of Jilin province, and A3-TI3 represent sectors of Heilongjiang province. Sector names are defined in Table 1

Sign $U$ can be able to judge the nature of the inter-relationships between sectors. There are four types of relationships in Table S12.

Table S12. Possible binary relations between sectors.

\begin{tabular}{|c|c|c|}
\hline & + & - \\
\hline+ & $(+,+)$ mutualism & $(+,-)$ exploitation \\
\hline- & $(-,+)$ exploited & $(-,-)$ competition \\
\hline
\end{tabular}


